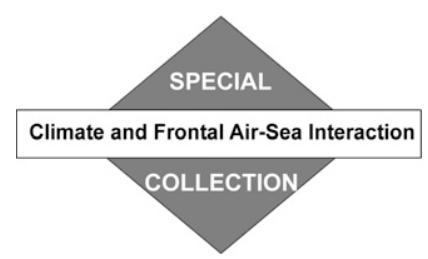

\title{
A Multivariate Estimate of the Cold Season Atmospheric Response to North Pacific SST Variability ${ }^{\mathcal{O}}$
}

\author{
AdÈle RÉVELARD AND Claude FranKIGNOUL \\ Sorbonne Université, LOCEAN/IPSL, Paris, France \\ YOUNG-OH KWON \\ Woods Hole Oceanographic Institution, Woods Hole, Massachusetts
}

(Manuscript received 2 February 2017, in final form 8 December 2017)

\begin{abstract}
The Generalized Equilibrium Feedback Analysis (GEFA) is used to distinguish the influence of the Oyashio Extension (OE) and the Kuroshio Extension (KE) variability on the atmosphere from 1979 to 2014 from that of the main SST variability modes, using seasonal mean anomalies. Remote SST anomalies are associated with each single oceanic regressor, but the multivariate approach efficiently confines their SST footprints. In autumn [October-December (OND)], the OE meridional shifts are followed by a North Pacific Oscillation (NPO)-like signal. The OE influence is not investigated in winter [December-February (DJF)] because of multicollinearity, but a robust response with a strong signal over the Bering Sea is found in late winter/early spring [February-April (FMA)], a northeastward strengthening of the Aleutian low following a northward $\mathrm{OE}$ shift. A robust response to the $\mathrm{KE}$ variability is found in autumn, but not in winter and late winter when the KE SST footprint becomes increasingly small and noisy as regressors are added in GEFA. In autumn, a positive PDO is followed by a northward strengthening of the Aleutian low and a southward shift of the storm track in the central Pacific, reflecting the surface heat flux footprint in the central Pacific. In winter, the PDO shifts the maximum baroclinicity and storm track southward, the response strongly tilts westward with height in the North Pacific, and there is a negative NAO-like teleconnection. In late winter, the North Pacific NPO-like response to the PDO interferes negatively with the response to the OE and is only detected when the OE is represented in GEFA. A different PDO influence on the atmospheric circulation is found from 1958 to 1977.
\end{abstract}

\section{Introduction}

Although the dominant influence of interannual sea surface temperature anomalies on the extratropical atmospheric circulation arises from El Niño-Southern Oscillation (ENSO) (e.g., Trenberth et al. 1998; Alexander et al. 2002), there is increasing observational and modeling evidence that extratropical SST anomalies also have significant impacts. Establishing their large-scale influence is a difficult task in observations, since the signal-to-noise ratio is small and cause and effect must

\footnotetext{
Supplemental information related to this paper is available at the Journals Online website: https://doi.org/10.1175/JCLI-D-170061.s1.
}

Corresponding author: Claude Frankignoul, cf@locean-ipsl. upmc.fr be distinguished, as the atmosphere drives the SST anomalies, and the instantaneous correlation between SST and atmospheric anomalies primarily reflects the atmospheric forcing of the ocean (Davis 1976; Frankignoul and Hasselmann 1977). The response to extratropical SST anomalies must thus be estimated by lagging the atmosphere by more than its intrinsic persistence (10 days at most), but less than the oceanic one (Frankignoul et al. 1998). As this is only valid if no other source increases both oceanic and atmospheric persistence, trends and ENSO teleconnections were generally removed. Using lag maximum covariance analysis (MCA), Liu et al. (2006) and Frankignoul and Sennéchael (2007) showed that a North Pacific SST anomaly resembling the Pacific decadal oscillation (PDO) significantly influences the late summer atmospheric circulation in the North Pacific; the latter authors also detected an SST anomaly influence in early winter. Gan and Wu (2013) similarly found 
significant North Pacific SST anomaly impacts on the storm track in early winter and suggested that the PDO influences the winter storm track at decadal time scale. Wen et al. (2010) used a different multivariate method, the Generalized Equilibrium Feedback Analysis (GEFA; Liu et al. 2008), to simultaneously investigate the atmospheric response to the main tropical and extratropical SST anomaly modes, thus taking into account their possible interference. The largest response was to SST anomalies in the equatorial Pacific and the Indian Oceans, but a response to the PDO was found: a strengthening of the Aleutian low and a remote downstream signal resembling the negative phase of the North Atlantic Oscillation (NAO). However, the response was only significant in winter (Liu et al. 2012). Although, as reviewed by Newman et al. (2016), most studies of the PDO have focused on its response to tropical and extratropical atmospheric forcing, lagged relations thus suggest that the PDO also feeds back onto the atmospheric circulation; further evidence is given in the present paper. Several observational studies (e.g., Dai 2013; Dong and Dai 2015) have focused on the low-frequency influence of the PDO, but they are based on simultaneous relations that do not distinguish between forcing and response, even at low frequency (Frankignoul 1999; Newman et al. 2016), nor do they always distinguish between tropical and extratropical SST influence.

These studies investigate the impacts of large-scale North Pacific SST anomaly modes that were largely driven by intrinsic atmospheric variability and ENSO teleconnections, although reemergence and ocean dynamics contribute to the PDO at low frequency (Schneider and Cornuelle 2005; Newman et al. 2016, and references herein). However, the variability of the narrow frontal zones associated with the Oyashio Extension (OE) or the Kuroshio Extension (KE) has an SST signature that may not appear as a dominant, basinwide SST anomaly mode, but play an important role in driving a large-scale atmospheric signal. Such oceanic fronts maintain surface baroclinicity and sustain storm development; this may anchor the storm track along the main oceanic frontal zones (Nakamura et al. 2004; Minobe et al. 2008; Taguchi et al. 2012). Observational (Joyce et al. 2009; Frankignoul et al. 2011, hereafter FSKA; Taguchi et al. 2012; Kwon and Joyce 2013; O'Reilly and Czaja 2015; Révelard et al. 2016) and modeling (Kwon and Deser 2007; Taguchi et al. 2012; Smirnov et al. 2015) studies suggest that the OE and KE variability significantly influences the atmosphere, but the observational results depend on the choice of OE or KE indices, and perhaps on the analysis period. Using an $\mathrm{OE}$ index based on the maximum meridional SST anomaly gradient, FSKA found that the response to the meridional OE shifts resembles the North Pacific Oscillation (NPO) and is stronger during the cold season. However, although care was taken to remove the influence of ENSO, the SST footprint of the frontal fluctuations includes weak SST anomalies of larger scale than expected from frontal changes, somewhat resembling the PDO. Similarly, the SST footprint of the KE variability in Révelard et al. (2016) shows an SST anomaly in the Kuroshio-Oyashio Extension (KOE) region, but also significant remote signals in the North Pacific, and the OE footprint in Taguchi et al. (2012) includes remote tropical and extratropical signals. These remote SST anomalies may occur because the atmospheric response to the frontal variability generates larger-scale SST patterns, as in the simulations of Kwon et al. (2011), or because large-scale SST anomalies are driven by the atmospheric fluctuations that affected the western boundary current extensions. They could also be due to the concomitant influence of other anomaly modes that were not represented, since SST anomalies in other basins and sea ice concentration (SIC) fluctuations also have remote impacts (e.g., Lau et al. 2005; Frankignoul et al. 2014). Smirnov et al. (2014) showed that ocean-driven SST anomalies in the North Pacific were essentially limited to the KOE region; hence Smirnov et al. (2015) limited the OE SST footprint to a narrow region along the mean OE path in sensitivity studies. We show below that multivariate analysis helps singling out the SST footprint of the frontal variability in observational studies.

To distinguish between the impacts of the $\mathrm{OE}$ and the KE variability and those of ENSO, the PDO, and other main SST modes in the observations, we use the GEFA method. We stratify the analysis by seasons, since modeling studies (Peng et al. 1997; Peng and Whitaker 1999; Liu and Wu 2004; Gan and Wu 2012) also stress that the response to boundary forcing varies with the season. We focus on the influence of the OE, the KE, and the PDO on the Northern Hemisphere atmospheric circulation in the cold season and distinguish between autumn [OctoberDecember (OND)], winter [December-February (DJF)], and late winter/early spring [February-April (FMA)].

\section{Data}

Monthly fields of sea level pressure (SLP) and geopotential height are taken at reduced $1.5^{\circ}$ resolution from the ERA-Interim reanalysis during the period 1979-2014 (Dee et al. 2011; www.ecmwf.int/en/research/ climate-reanalysis/era-interim), while an original $0.75^{\circ}$ resolution is used for air temperature, wind velocity, and surface heat flux. The turbulent heat fluxes of the OAFlux product (Yu and Weller 2007; http://oaflux. whoi.edu) were also considered, with similar results. The maximum Eady growth rate $\sigma=0.31|f| \times \mid \partial \mathbf{V}(z) /$ $\partial(z) \mid / N$ where $f$ is the Coriolis parameter, $\mathbf{V}(z)$ is the 


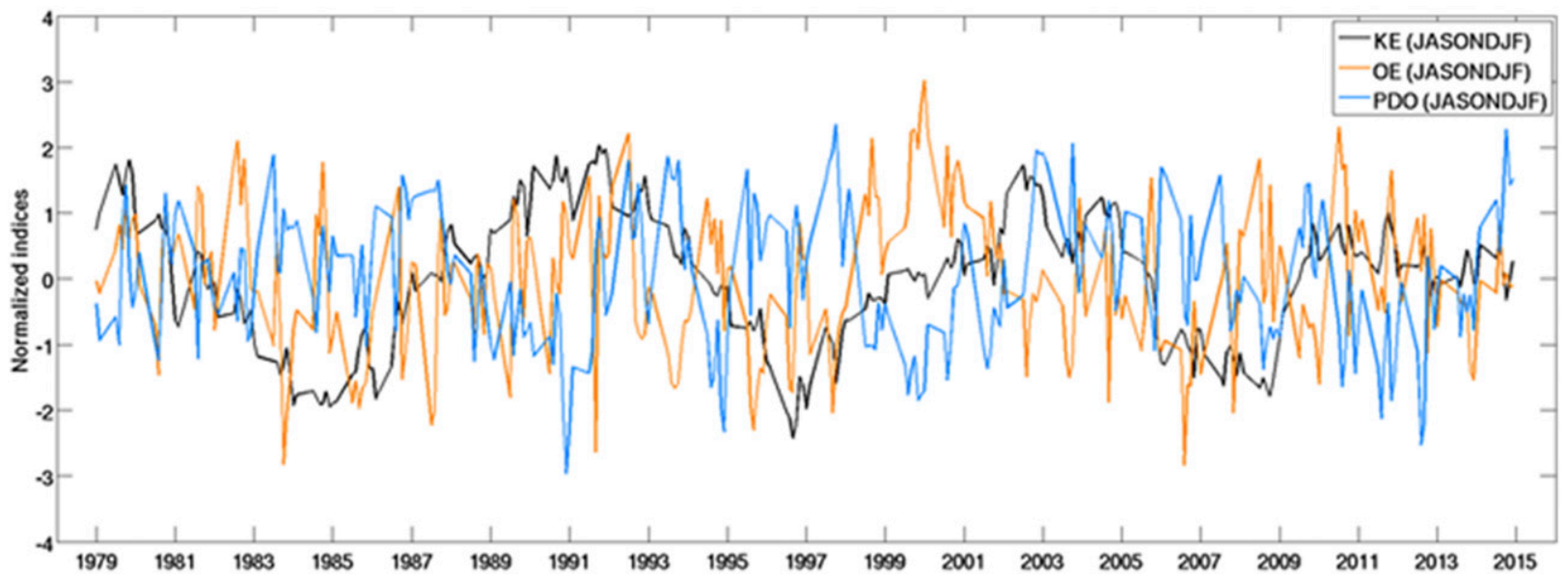

FIG. 1. Standardized detrended monthly KE index (black), OE index (orange), and PDO index (blue) in the JASONDJF season.

horizontal wind vector, and $N$ is the Brunt-Väisälä frequency, is estimated at $850 \mathrm{hPa}$. The transient meridional eddy heat flux at $850 \mathrm{hPa}$ and the storm track at $500 \mathrm{hPa}$ (the root-mean-square of $500-\mathrm{hPa}$ geopotential height) are estimated from high-pass daily values, using the Blackmon filter to retain fluctuations within a period of 2 to 8 days (Blackmon and Lau 1980). Monthly anomalies are obtained by subtracting the first two annual harmonics of the mean seasonal cycle and removing a cubic trend (a linear trend yields very similar results). The oceanic variables are treated similarly.

A main goal of this study is to single out the cold season atmospheric response to the variability of the $\mathrm{OE}$ and the KE, and to distinguish it from that of the main North Pacific SST modes, which was not attempted in previous studies. This motivates our use of representative indices of the KE and the OE variability, and of the main SST anomaly modes, even though they may be significantly correlated. The variability of the $\mathrm{KE}$ is represented by the index of Qiu et al. (2014), defined by the SSH anomaly averaged in $31^{\circ}-36^{\circ} \mathrm{N}, 140^{\circ}-165^{\circ} \mathrm{E}$. A positive KE index denotes a stable state in which the KE jet has a steady and northerly path, increased surface transport, an enhanced southern recirculation gyre, and decreased eddy kinetic energy. A negative KE index reflects the reversed properties. The KE index (Fig. 1) is based on satellite altimetry starting in October 1992, and earlier on a hindcast with the eddy-resolving OFES model, which captures the KE decadal variability realistically (the correlation between model output and satellite-based data is $r=0.81$ for the overlapping 19922012 period; see Qiu et al. 2014 for details). The OE variability is represented by its meridional shifts defined by the leading principal component (PC) of the latitude of the maximum meridional SST gradient between $145^{\circ}$ and $170^{\circ} \mathrm{E}$ (Fig. 1), as in FSKA, except that it is based on the OAFlux SST with $1^{\circ}$ resolution instead of the NOAA OISST with $0.25^{\circ}$ resolution. In the overlapping 1982-2014 period, the two indices have a correlation $r=0.66(r=0.82$ after a 1-yr Butterworth low-pass filter is applied) and lead to similar results.

The SST is taken from ERA-Interim, excluding grid points where the March SIC climatology from ERAInterim exceeds $5 \%$. The resolution of SST used as the boundary condition for ERA-Interim is $1^{\circ}$ until 2001, $0.5^{\circ}$ since 2002 , and $0.05^{\circ}$ since February 2009 . Masunaga et al. (2015) have shown that the improvement of the resolution of the prescribed SST in ERA-Interim exerts substantial impacts on the representation of the marine atmospheric boundary layer, cloudiness, and precipitation; Parfitt et al. (2017) showed that the strongest sensible heat flux gradient since 2010 affected the atmospheric fronts passing across the Gulf Stream region. Hence, our analysis of the local influence of the frontal variability associated with the $\mathrm{OE}$ and the KE should be viewed with caution. Nonetheless, Révelard et al. (2016) found that the large-scale response to the KE variability estimated from the NCEP-NCAR reanalysis (Kalnay et al. 1996) that has a lower resolution (T63) was similar to that based on ERA-Interim. This suggests that data assimilation is sufficient to strongly constrain the atmospheric flow, and that the lower SST resolution until 2002 does not significantly influence our estimates of the large-scale responses to frontal variability. Large-scale SST patterns should not be significantly affected by the changes in SST resolution, and we verified that highly similar SLP and geopotential height responses were found during the period 1982-2014 when using the $0.25^{\circ}$ NOAA OISST data (Reynolds et al. 2007) to define the EOFs. The SST variability is mostly represented by rotated empirical orthogonal functions (R-EOFs) and rotated 

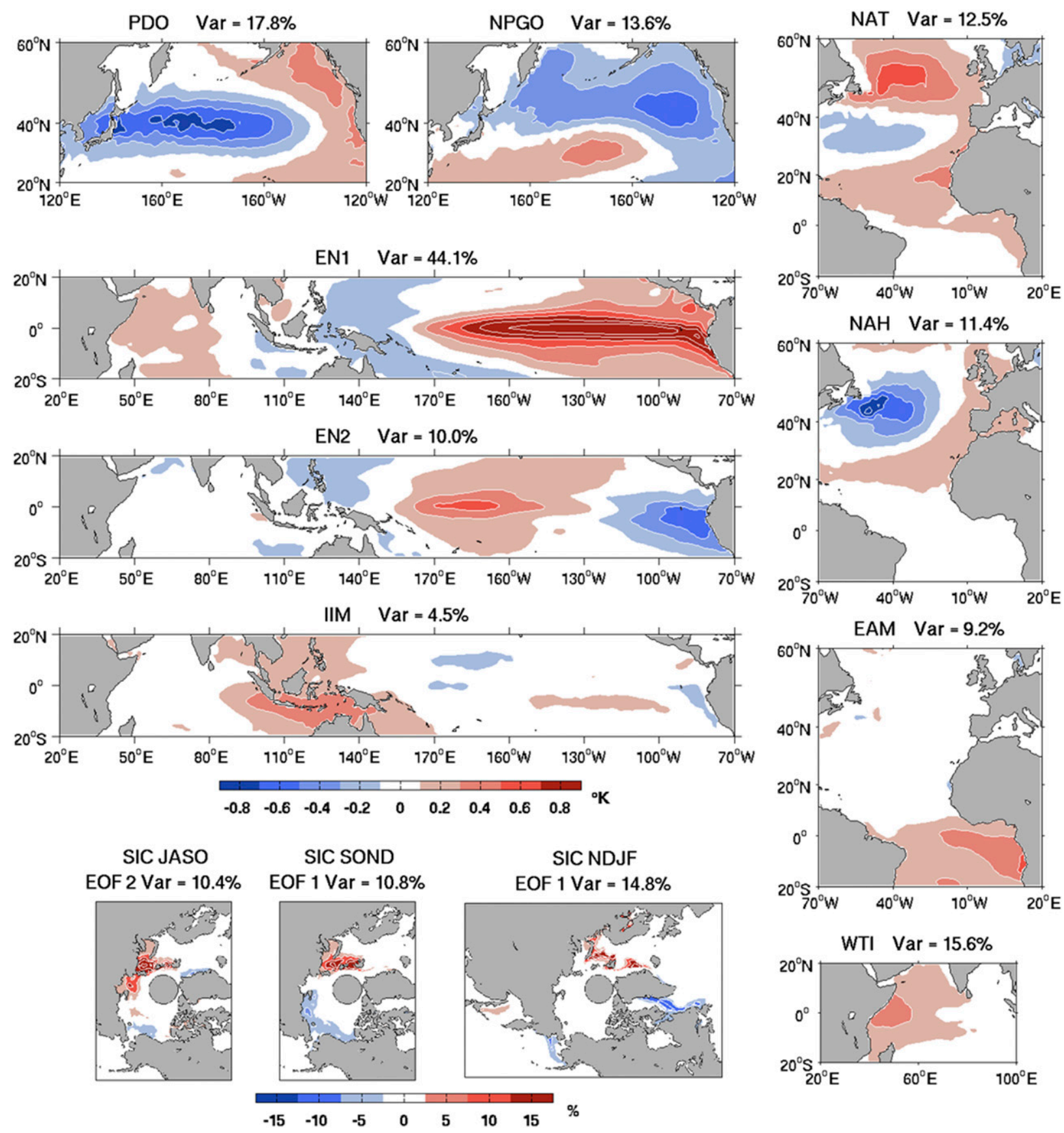

FIG. 2. Selected SST R-EOFs or EOFs in JASONDJF [contour interval (CI) $0.2 \mathrm{~K}$ ] and SIC EOF (\%) for JASO, SOND, and NDJF. The percentage of represented variance in each basin is indicated.

principal components (R-PCs) calculated in different domains (Fig. 2). As R-EOFs are not constrained to be spatially orthogonal, they are well adapted to describing the time evolution of climate modes, and they are generally more robust than EOFs (e.g., Cheng et al. 1995). To focus on the cold season and obtain robust patterns while limiting sampling uncertainty, they are calculated for July-February (JASONDJF), since the atmospheric response is estimated between October and April from oceanic anomalies 2 or 3 months earlier (section 3). The ocean is divided into the tropical Indo-Pacific (TIP; $\left.20^{\circ} \mathrm{S}-20^{\circ} \mathrm{N}, 20^{\circ} \mathrm{E}-70^{\circ} \mathrm{W}\right)$, the tropical Indian $\left(20^{\circ} \mathrm{S}-20^{\circ} \mathrm{N}\right.$, $20^{\circ}-100^{\circ} \mathrm{E}$ ), the North Pacific (NP; $20^{\circ}-60^{\circ} \mathrm{N}, 120^{\circ} \mathrm{E}-$ $\left.120^{\circ} \mathrm{W}\right)$, and the Atlantic $\left(20^{\circ} \mathrm{S}-60^{\circ} \mathrm{N}, 70^{\circ} \mathrm{W}-20^{\circ} \mathrm{E}\right)$. In the TIP, the first R-PC [El Niño 1 (EN1)] is highly correlated with the Niño 3.4 index $(r=0.94)$, while the 
second [E1 Niño 2 (EN2)] is highly correlated with the Trans-Niño index $(r=-0.94)$ that mostly represents the decay of the El Niño events following their winter peak (Trenberth and Stepaniak 2001), and with the El Niño Modoki index $(r=0.87)$ of Ashok et al. (2007). The third R-EOF is a monopole in the Indonesian Seas and the eastern Indian Ocean [Indonesian Indian monopole (IIM)], which is moderately correlated with the Indian Ocean dipole (Saji et al. 1999; $r=-0.55$ ). To represent the SST variability in the western and central Indian Ocean, which is not represented by the first three TIP R-EOFs (nor by the fourth one), we use the first R-EOF of the Indian Ocean SST anomaly residuals obtained after regressing out the variability correlated with the three TIP R-PCs. It represents a warming in the western Indian Ocean (hereafter WTI); its R-PC is weakly correlated with the Indian Ocean dipole $(r=0.37)$. In the Atlantic, we use the first three R-EOFs: the first one resembles the North Atlantic tripole (NAT), the second broadly resembles the North Atlantic horseshoe pattern (NAH; Czaja and Frankignoul 2002), and the third is the equatorial Atlantic (or Atlantic Niño) mode (EAM; Zebiak 1993; Wang 2002). In the North Pacific, we use standard EOFs as in Mantua et al. (1997) and Bond et al. (2003). The first EOF represents the PDO (Mantua et al. 1997), and its PC is also shown in Fig. 1. The second EOF represents the North Pacific Gyre Oscillation (NPGO; Di Lorenzo et al. 2008). To better distinguish between the influence of the OE, which is significantly correlated with the PDO ( $r=-0.4$ in JASONDJF), we have also defined North Pacific SST indices as the leading North Pacific EOFs calculated with the KOE region $\left(30^{\circ}-45^{\circ} \mathrm{N}\right.$, $130^{\circ} \mathrm{E}-180^{\circ}$ ) excluded from the calculation (hereafter PDO-KOE and NPGO-KOE, collectively referred to as NP-KOE). As seen below, the cooling in the KOE region is weaker in the PDO-KOE footprint, and the warming along the U.S. West Coast is larger; its PC is well correlated with the standard PDO $(r=0.63)$, but less correlated with the OE index $(r=-0.25)$. This should help singling out the response to the OE.

SIC is taken from the passive microwave monthly data provided by the National Snow and Ice Data Center (Comiso 2000). Because of the strong seasonal and longterm variations of the sea ice edge, SIC is represented differently. At each grid point, SIC anomalies are obtained for each calendar month separately by subtracting a cubic trend and its long-term mean. EOFs are then calculated for each season, keeping only grid points where the seasonal climatological SIC is $<90 \%$ and $>2 \%$ (R-EOFs give very similar results). We found that the addition of the SIC modes in GEFA has little impact on our estimation of the atmospheric response to the other oceanic forcing, and only one EOF (Fig. 2) has a significant impact in each season, namely the second EOF (SIC2) in July-October (JASO) for autumn, which describes increasing SIC in the Barents-Kara Seas, the first EOF (SIC1) in September-December (SOND) (SIC increase in the Barents Sea and decrease in the Chukchi Sea) for winter and in November-February (NDJF) (SIC increase in the Barents and Greenland Seas and the Sea of Okhotsk, and decrease in the Labrador and Bering Seas) for late winter. Hence, only these PCs are included in the analysis discussed below.

In total, 12 oceanic explanatory variables or regressors are considered. They are not independent and the associated SST anomalies extend much beyond their domain of definition. This is illustrated for AugustOctober (ASO) in Fig. 3 (left), where the SST pattern $a_{j}$ associated with $j$ th regressor is obtained from the regression $\mathbf{T}(t)=Y_{j}(t) \mathbf{a}_{j}+\mathbf{e}(t)$, where $\mathbf{T}(t)$ is the SST anomaly field at every grid point, $Y_{j}(t)$ is the regressor time series, $e(t)$ is the residual, and $t$ is in months. For instance, EN1 has a PDO-like extension in the North Pacific, and the PDO is associated with equatorial $\mathrm{Pa}$ cific warming, reflecting the influence of ENSO on the PDO (e.g., Lau and Nath 1996; Schneider and Cornuelle 2005; Newman et al. 2016). In fact, most regressors are associated with equatorial Pacific SST anomalies or substantial cross-basin correspondences, reflecting atmospheric bridges, coordinated atmospheric forcing, and sample limitation. Hence, univariate estimates of the atmospheric response would be confounded by the complexity of the oceanic forcing. On the other hand, when the oceanic time series are considered simultaneously, the SST anomaly patterns $\mathbf{a}_{i}^{\prime}$, derived from the multiple regression $\mathbf{T}(t)=\sum_{1}^{12} Y_{j}(t) \mathbf{a}_{j}^{\prime}+\mathbf{e}^{\prime}(t)$, become largely regional (Fig. 3, right). The remote SST signature of the KE and the OE is largely gone, the PDO and the NPGO have no signatures in the equatorial band, the extratropical signatures of EN1 and EN2 are largely removed, IIM resembles TIP R-EOF3 as defined, the SST anomalies associated with NAT, NAH, EAM, and WTI are limited to their initial domain, and SIC2 becomes primarily associated with a Norwegian Sea warming. Although EN1 remains associated with an Indian Ocean warming in each season, reflecting the atmospheric bridge between ENSO and the Indian Ocean (Schott et al. 2009), and small remote patchy SST anomalies remain, the multivariate approach strongly modifies the SST imprint of each regressor, leading to more localized SST anomalies and a better separation between tropical and extratropical forcing. This is an interesting aspect of GEFA that was not noted in earlier applications. In previous GEFA studies, the attention has been paid to the atmospheric response to the different SST modes, but not to their SST footprint. Here, the global SST field is used 


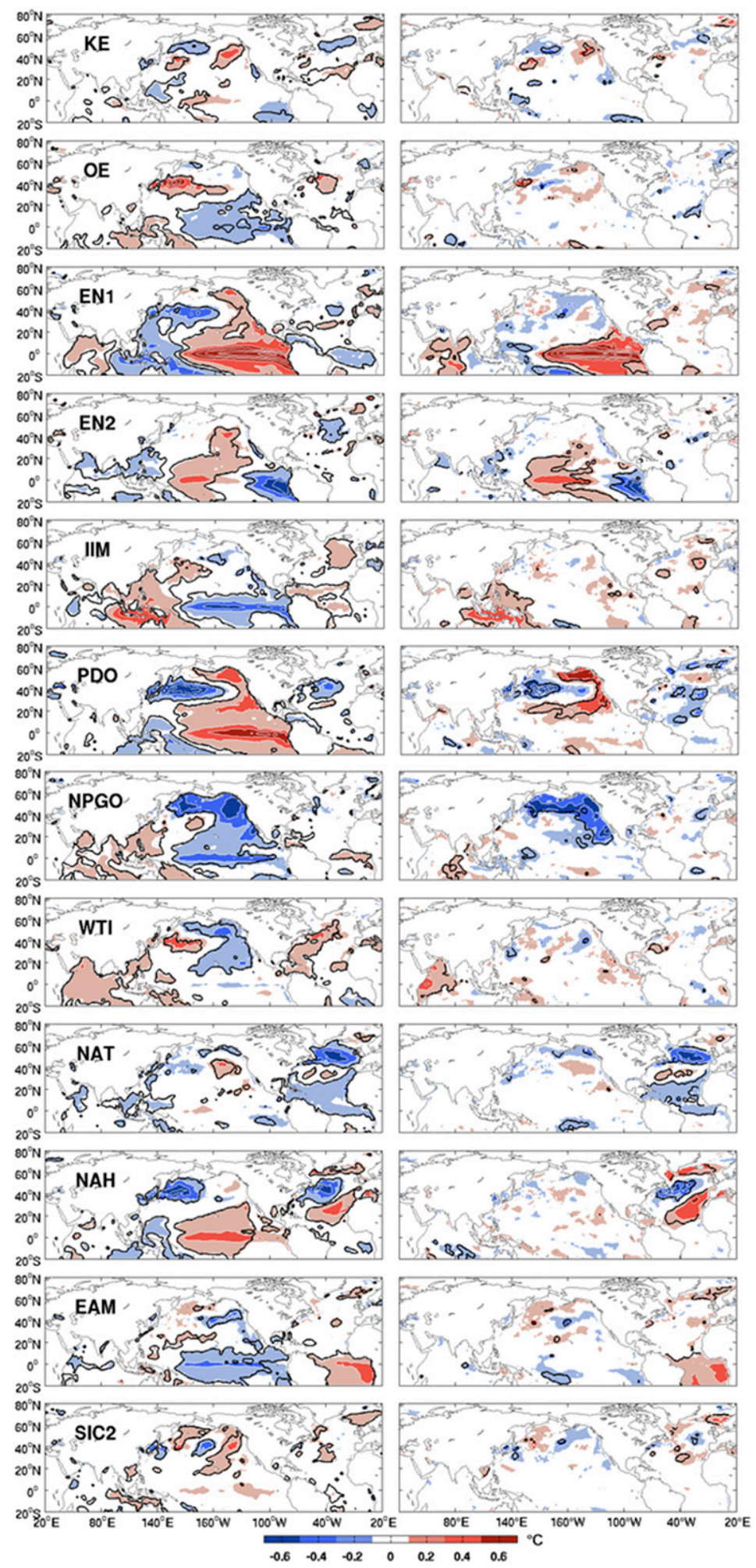

FIG. 3. SST footprint (K) in ASO of each oceanic regressor, as indicated, in (left) univariate and (right) multiple regressions. Black contours indicate $10 \%$ significance. 
to show the SST footprint of the different SST modes when they are considered simultaneously, allowing for a clearer attribution of their impact on the atmosphere. Note that the separation between EN1 and PDO is opposite to that in Chen and Wallace (2016), where the ENSO signal was limited to a narrower equatorial band and the PDO kept the equatorial component that characterizes its decadal variations. In the present paper, the atmospheric response to the PDO should be understood as the response to the extratropical part of the PDO. This is a reasonable decomposition in the present context, since the response to tropical and extratropical SST anomalies results from largely different mechanisms.

\section{Multivariate estimation of the atmospheric response}

\section{a. The statistical model}

We assume that, at each grid point, an atmospheric anomaly $Z(t)$ can be described as the sum of a linear function of the $J$ time series $Y_{j}(t)$, and an uncorrelated stochastic internal variability $n(t)$. We also assume that the atmospheric response is not instantaneous but takes a time $d$ to reach its maximum amplitude. This is written

$Z(t)=\mathbf{B Y}(t-d)+n(t)=\sum_{j=1}^{J} b_{j} Y_{j}(t-d)+n(t)$,

where $\mathbf{B}$ is the response (feedback) matrix, with $b_{j}$ representing the impact of the $j$ th forcing (regressor) on $Z$, and $\mathbf{Y}(t)$ is the regressor vector. Several studies suggest that $d=1-2$ months is appropriate for the extratropical atmosphere (Hoerling et al. 2004; Ferreira and Frankignoul 2005; Deser et al. 2007), but recent highresolution experiments indicate that the local response to fronts may be slightly faster (Smirnov et al. 2015). The value of $d$ can be derived from the lag regression of, say, monthly SLP anomalies onto the oceanic indices, as for the PDO in Fig. 4. The regression maps are based on multiple regression (univariate regression would confuse tropical and extratropical SST forcing), except at lag -1 (atmosphere leads by 1 month), which represents the forcing of the PDO by the Aleutian low variability (e.g., Schneider and Cornuelle 2005) and is therefore computed with univariate regression. Consistent with the stochastic climate model (Frankignoul and Hasselmann 1977), lag 0 is also dominated by the PDO response to the atmosphere. When the PDO leads, the SLP pattern changes drastically, with small amplitude and limited statistical significance at lag 1, larger amplitude and significance at lag 2 , and in most seasons, smaller magnitude at lag 3 . This suggests that $d=2$ months is an appropriate choice, and again stresses that the response to extratropical SST anomalies cannot be estimated from unlagged relations. Throughout this study, statistical significance is tested with a Monte Carlo method, randomly permuting the atmospheric time series 500 times in blocks of $3 \mathrm{yr}$ (von Storch and Zwiers 1999).

If the maximum atmospheric response occurs after $d$ months, one should search for it at lag $\geq d$. Since $d+\tau$ is longer than the persistence time of $n$, one easily finds from (1)

$$
\mathbf{B}=\frac{\mathbf{C}_{Z \mathbf{Y}}(d+\tau)}{\mathbf{C}_{\mathbf{Y Y}}(\tau)}
$$

where $\mathbf{C}_{Z \mathbf{Y}}$ is the covariance matrix between $Z$ and $\mathbf{Y}$ at $\operatorname{lag} d+\tau$, and $\mathbf{C}_{\mathbf{Y Y}}(\tau)$ the covariance matrix of $\mathbf{Y}$ at a lag $\tau$. All oceanic time series are standardized, hence $\mathbf{C}_{\mathbf{Y Y}}(\tau)$ is a correlation matrix and $\mathbf{B}$ gives typical response magnitude. See Liu et al. (2008) and Wen et al. (2010) for further details on GEFA. To increase the signal-tonoise ratio, we work with seasonal (3 month) means, and to separate cause and effect, we choose $d+\tau=3$ month hence $\tau=1$ month which minimizes $\tau$ and consequently achieves a better condition on $\mathbf{C}_{\mathbf{Y Y}}(\tau)$, hence a reduced sampling error in (2). Our estimated response (Fig. 4, lower panels) based on a lag of one season (lag 3) is reasonably similar to the multiple regression based on monthly anomalies at lags 2 and 3 (Fig. 4). If we had chosen $d=1$ month while using seasonal means, cause and effects would only be separated at $\tau \geq 2$ months, which would lead to much larger sampling errors. However, we verified using monthly data that the estimated responses based on $d=1$ month, $\tau=1$ month, thus estimated at lag 2, are largely similar to those estimated from seasonal averages, ${ }^{1}$ except in the very few cases where the month-to-month persistence of a regressor is small, which leads to much larger amplitude. This is illustrated in Fig. 5 for the OE in OND when its autocorrelation at lag 1 is only 0.58 (compared with 0.89 using seasonal averages); by contrast, the $\mathrm{KE}$ is more persistent and a similar response is obtained by the two methods. Hence, using seasonal averages leads to less noisy, more persistent regressors, which reduces the sensitivity of the response estimates. See Fig. 19 below for another comparison. Note that a 2-month atmospheric response time was also used in FSKA and Révelard et al. (2016). On the other hand, the response was assumed to be fast $(d=0)$ and estimated at a lag of

\footnotetext{
${ }^{1}$ The response based on $d=2$ months; $\tau=0$ month is also similar, but with a smaller amplitude.
} 

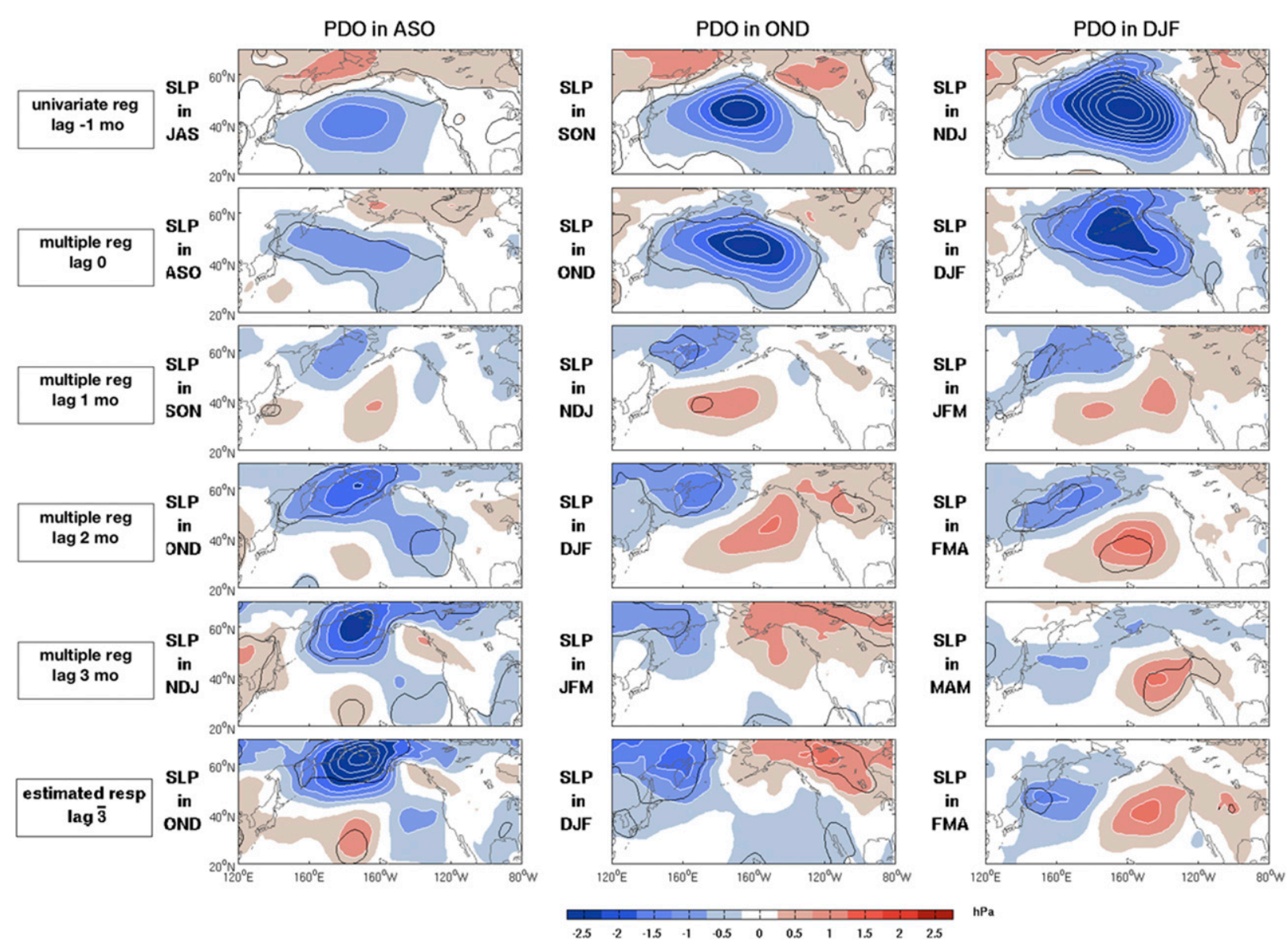

FIG. 4. (upper row) Univariate regression of monthly SLP anomalies (hPa) on the PDO index in (left) ASO, (middle) OND, and (right) DJF with the PDO lagging by 1 month; the SLP months are indicated. (rows 2-5) As above, but for multiple regression on the PDO index leading by $0,1,2$, and 3 months. (bottom row) GEFA estimate of the seasonal mean SLP response. Black contours indicate $10 \%$ significance.

$\tau=1$ month in previous GEFA applications (Wen et al. 2010; Liu et al. 2012).

\section{b. Multicollinearity}

The advantage of GEFA is that it should separate the atmospheric response to different oceanic forcing. However, (2) requires inverting the matrix $\mathbf{C}_{\mathbf{Y Y}}(\tau)$, which is not symmetric and may yield much multicollinearity if the regressors are strongly correlated or insufficiently persistent, making it difficult to separate their influence. Multicollinearity can be assessed by the condition number, the ratio between the largest and smallest singular values of $\mathbf{C}_{\mathrm{YY}}(\tau)$. If it is low (typically $<10$ ), the matrix is well conditioned and its inverse can be accurately computed. In this study, the condition number never exceeds 3 . However, Stewart (1987) showed that the condition number is too crude an indicator of collinearity. Multicollinearity is better quantified by the variance inflation factor (VIF; Kendall
1946). The VIF is the factor $1 /\left(1-R_{j}^{2}\right)$, by which the variance of a univariate estimator of $b_{j}$ is increased by considering the other regressor variables, where $R_{j}^{2}$ is the $R$-squared value (coefficient of multiple determination) obtained by regressing the $j$ th regressor on the remaining ones, hence the proportion of the variance of $Y_{\mathrm{j}}$ that is explained by the other regressors. If the correlation of $Y_{\mathrm{j}}$ with the other regressors is large, so is $R_{j}^{2}$, resulting in a high variance of $b_{j}$. The VIFs are also the diagonal elements of the inverse correlation matrix $\mathbf{C}_{\mathbf{Y Y}}(\tau)^{-1}$, which is how they are calculated. A general rule is that VIFs exceeding 5 are signs of severe multicollinearity (Judge et al. 1988), so we only consider results when the VIFs are smaller than 4.

The matrix $\mathbf{C}_{\mathbf{Y Y}}(\tau)$ used to estimate the atmospheric response in OND is shown in Fig. 6. Each column $j$ gives the correlation between the $j$ th regressor and the others one month earlier; high correlations indicate the regressors that most contribute to the univariate response 


\section{Z250 for KE}
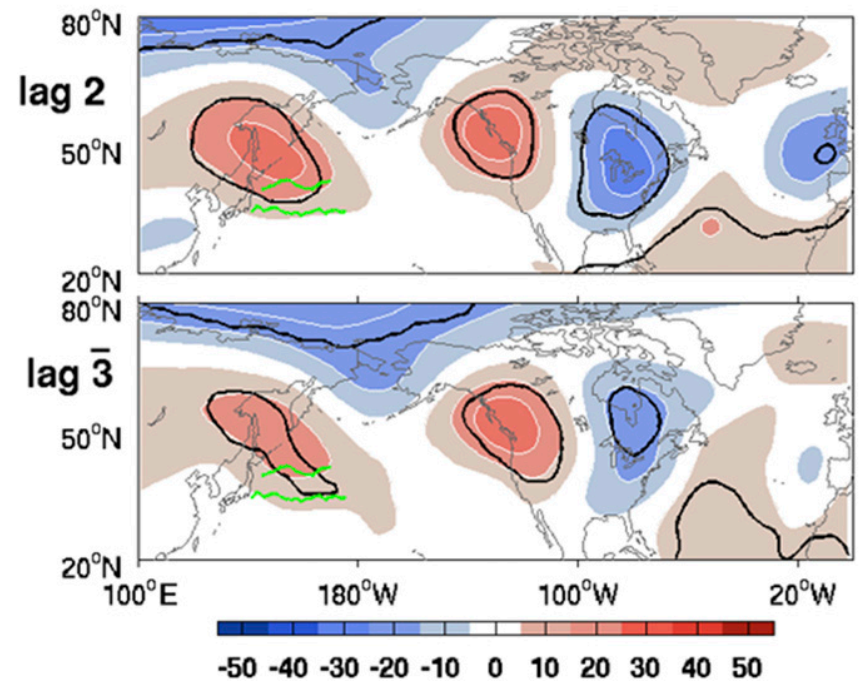

\section{Z250 for OE}
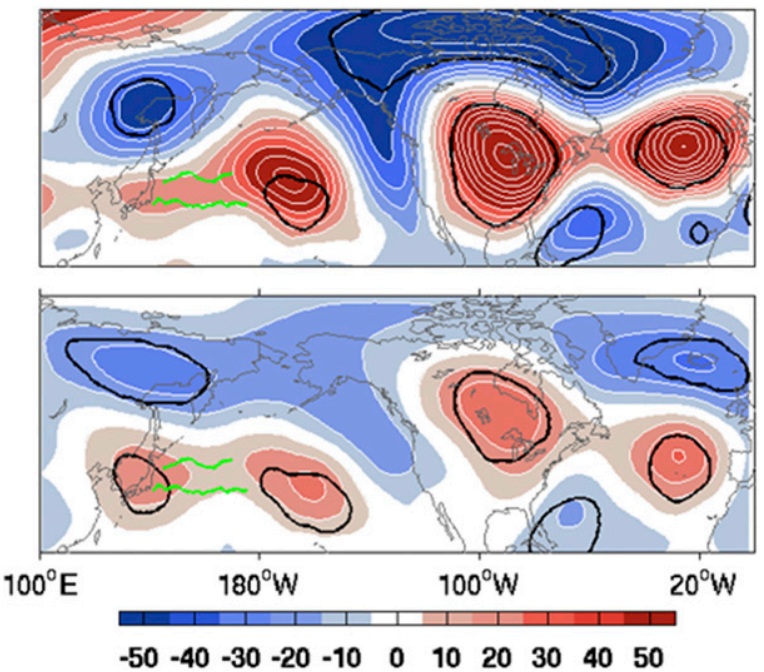

FIG. 5. Estimated response in OND of the geopotential height at $250 \mathrm{hPa}(\mathrm{m})$ to (left) the KE and (right) the OE as estimated by GEFA based on (top) monthly data with $d=1$ month and (bottom) seasonal means with $d=2$ months.

to the $j$ th forcing. As the maximum VIF is 2.73 , there is no strong problem of multicollinearity. For DJF, the VIF reaches 4.11 for the OE and 3.58 for the NPGO, reflecting the stronger correlation between many regressors (not shown). To reduce the sampling errors, it is advisable to reduce the number of explanatory variables. We tried omitting various combinations of regressors while keeping all the North Pacific ones, but none of them led to even satisfactorily isolating the $\mathrm{OE}$ SST footprint in this season. Hence the OE regressor is omitted, substantially lowering the VIFs, which become $<2.5$, except 3.29 for NPGO. The latter value is relatively high, but it was verified that omitting the NPGO would barely affect the analysis. In FMA, multicollinearity is limited, although the VIF reaches 3.68 for EN1 and 3.61 for IIM (not shown), reflecting their high correlation. This leads to an artificially large response to EN1 and IIM but does not affect the response to the other regressors, as verified by omitting IIM.

\section{Atmospheric response}

\section{a. The full GEFA results}

Since the SST footprints of the oceanic regressors that could generate an atmospheric response are largely confined to their region of definition, and multicollinearity is limited, we are fairly confident that the estimated seasonal mean atmospheric response to each oceanic forcing largely reflects its impact. Before discussing the responses to the $\mathrm{OE}$, the $\mathrm{KE}$, and the $\mathrm{PDO}$, those to the other oceanic modes are briefly discussed. The responses in OND are shown in Fig. 7 for the geopotential height at
$250 \mathrm{hPa}$ (Z250). The response to EN1 is a circumglobal high in the tropics with maximum amplitude in the tropical Pacific (barely seen in Fig. 7, which is limited to $20^{\circ} \mathrm{N}$ ), a strong elongated low over the northeastern $\mathrm{Pa}-$ cific, and a weakening of the Siberian high, typically reaching 20 to $40 \mathrm{~m}$. This is consistent with the atmospheric bridge (Alexander et al. 2002), but the upper-level ridge that was seen over western Canada as a response to ENSO is primarily attributed here to the (extratropical) PDO. On the other hand, our estimated OND response to EN1 is quite similar to the SON response in Liu et al. (2012). Except for an elongated high over northern Eurasia that is most significant in SLP (not shown), EN2 drives little extratropical response (even with fewer regressors or univariate regression), but IIM has a strong barotropic impact, with a large positive anomaly over the polar region and primarily negative anomalies at midlatitude, thus weakening the polar vortex. There is no significant atmospheric response to the NPGO or the WTI. The NAT primarily drives a small baroclinic response in the North Atlantic, and a barotropic wave-like signal propagating westward, while the NAH drives a negative NAO-like pattern as in Czaja and Frankignoul (2002), plus an upper-tropospheric teleconnection with a significant trough over Alaska. The EAM primarily leads a stationary wave in the upper troposphere with a ridge in the tropical North Atlantic, a weak trough off western Europe, a ridge over the Barents Sea, and a strong trough over Siberia. This response pattern already appears in univariate regression and has some limited similarity with the east Atlantic pattern-like response detected by Frankignoul and Kestenare (2005). Haarsma 


\section{Lag Correlation Matrix OND}

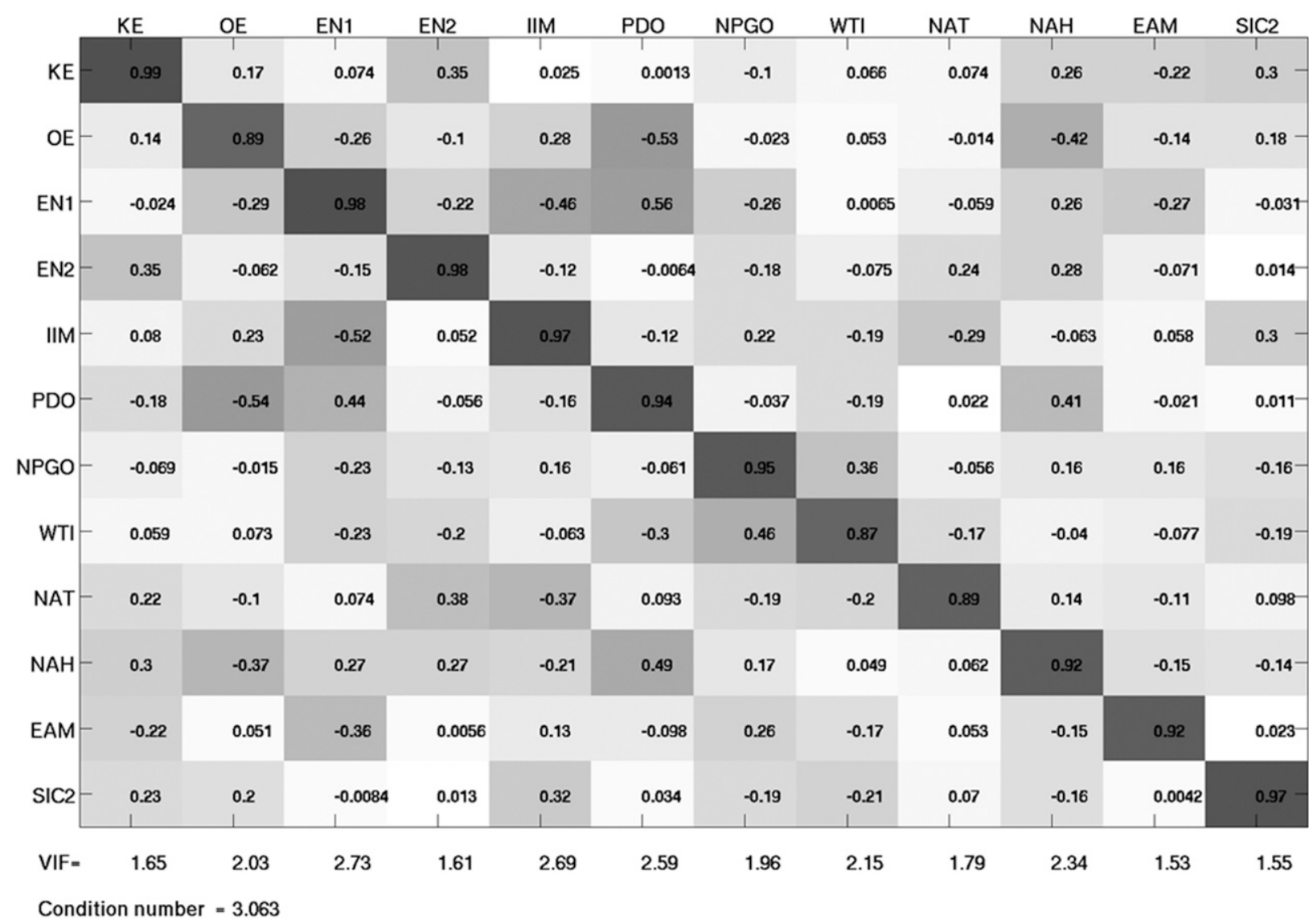

FIG. 6. Lag correlation matrix of (left to right) the 12 oceanic regressors, as indicated, used to estimate the atmospheric response in OND. Each row and column use seasonal mean anomalies in ASO and JAS, respectively. The VIF is indicated. Gray shading goes from -1 to 1 , with darker gray indicating higher absolute values, and lighter gray lower ones.

and Hazeleger (2007) showed that in a coupled model the equatorial warming generated a sufficiently large upperlevel divergence during late summer to induce a significant extratropical Rossby wave in fall and early winter. Finally, SIC2 primarily leads a barotropic signal over the North Atlantic that is broadly consistent with the NAO, as in García-Serrano et al. (2015), albeit shifted east.

In winter (OE excluded; supplemental Fig. 1 in file JCLI-D-17-0061s1) and late winter (not shown), the multivariate analysis also effectively localizes the SST footprints. Some interbasin connections remain for IIM, WTI, and NAT in DJF, and for NAT in FMA, but they are unlikely to significantly affect the response to the main North Pacific regressors. As our focus is on the latter, we only note that the winter responses to tropical regressors reproduce some standard results, in particular the familiar Pacific-North American (PNA)-like teleconnection driven by EN1 (e.g., Horel and Wallace 1981). This will be discussed elsewhere.

\section{b. Response to the OE variability}

The effect of increasing the number of oceanic regressors in GEFA on the estimated SLP and Z250 response to the OE in OND is shown in Fig. 8, together with the corresponding OE SST footprint estimated two months earlier in ASO. The univariate case (not represented) is contaminated by the tropics as OE is correlated with EN1 $(r=-0.25)$ and IIM $(r=0.32)$ (Fig. 3). Adding the 3 TIP regressors leads to a somewhat more localized SST footprint and largely suppresses the equatorial Pacific SST anomalies. Adding the PDO, which is highly correlated to the $\mathrm{OE}(r=-0.55)$, confines the SST warming to the mean OE path, west of $170^{\circ} \mathrm{E}$, and slightly reduces its amplitude to $0.6^{\circ} \mathrm{K}$, but a PDO-like pattern has appeared, albeit with very small amplitude and low significance, and becoming even smaller when all regressors are considered. In each case, the estimated atmospheric response is an equivalent 

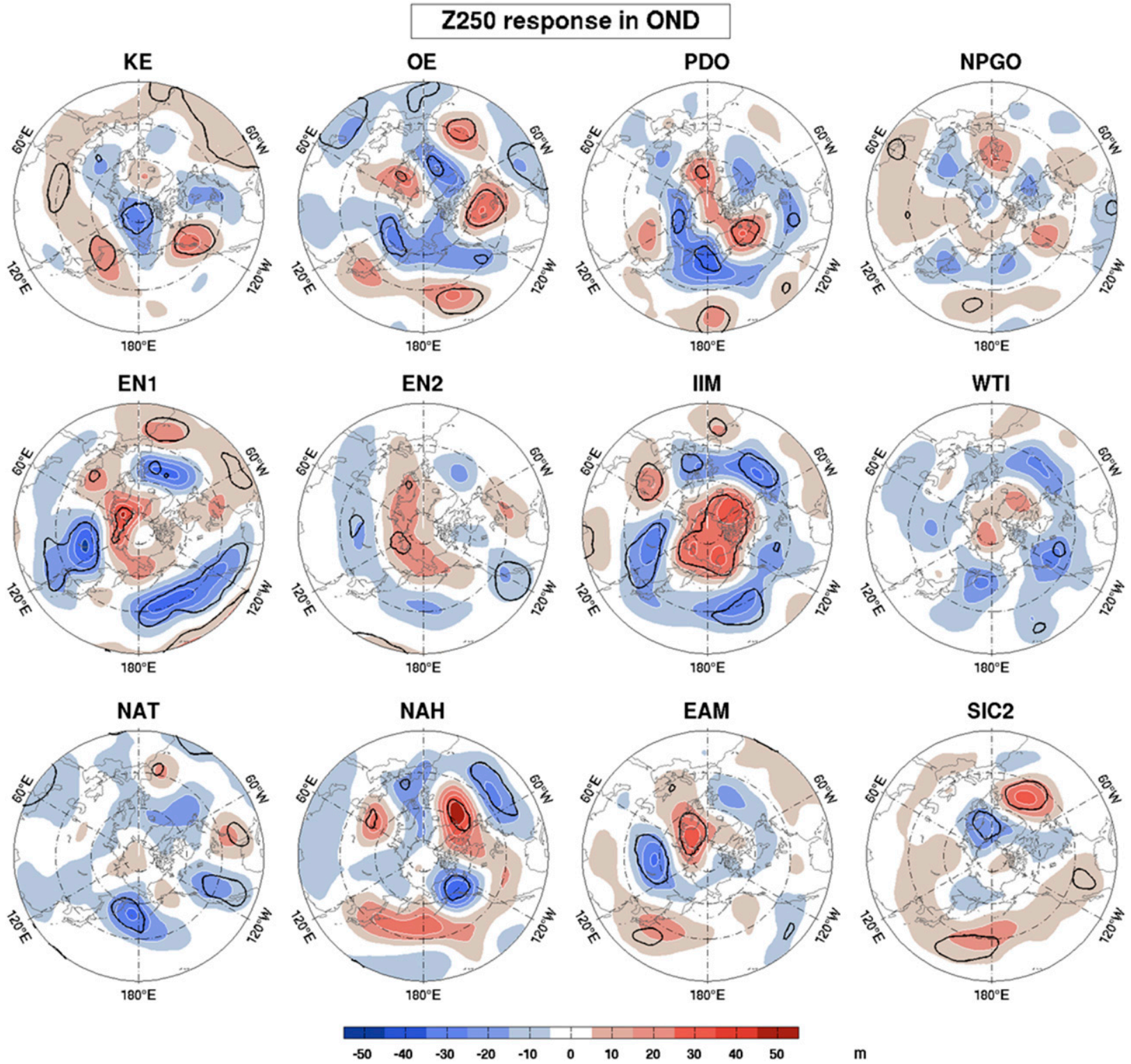

FIG. 7. Estimated response in OND of the geopotential height at $250 \mathrm{hPa}(\mathrm{m})$ to the 12 oceanic regressors, based on seasonal mean anomalies. Black contours indicate $10 \%$ significance. Lat circles are shown every $20^{\circ}$, starting at $20^{\circ} \mathrm{N}$.

barotropic high downstream of the KOE region and a northeastward-propagating wave, with a weak low off the Oregon coast and a strong upper-tropospheric high over northeastern America, reaching about $35 \mathrm{~m}$ at $250 \mathrm{hPa}$ (Fig. 8); there is also a weak high over the western KOE, but its significance is limited. As soon as the PDO is included in GEFA, a strong elongated low centered in the North Pacific around $60^{\circ} \mathrm{N}$ appears, with a 1.5-hPa low-level center of action over the Gulf of Alaska and a 30-m upper-level trough farther west over northeastern Asia. The atmospheric response then broadly resembles the NPO and its western Pacific (WP) teleconnection, including an NAO-like signal (Fig. 7).
Linkin and Nigam (2008) showed that the NPO/WP variability is linked to meridional movements of the Asian-Pacific jet and Pacific storm-track modulation, and perhaps driven by transient eddy forcing.

To assess the robustness of these estimates and further differentiate OE and PDO forcing, GEFA was also performed using NP-KOE instead of the standard PDO and NPGO (Fig. 8, bottom row). The OE SST footprint is stronger $\left(0.8^{\circ} \mathrm{K}\right)$ and a little broader, and the weak PDO-like signal disappears, so that this case perhaps best singles out the influence of the OE meridional shifts. Nonetheless, the estimated atmospheric response remains similar, although the high off Japan is strengthened 

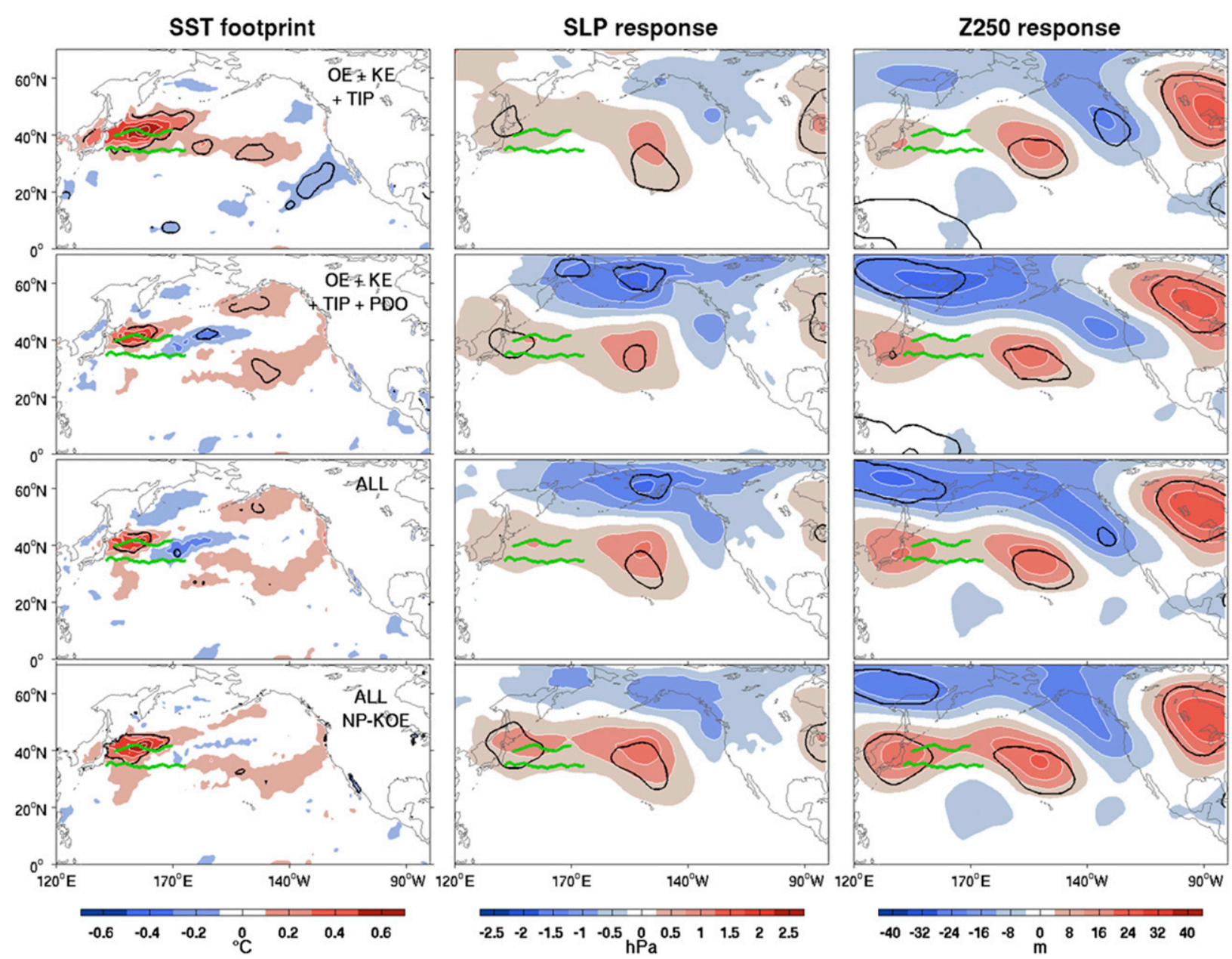

FIG. 8. (left) SST footprint (K) of the OE in ASO and response in OND of (middle) SLP (hPa) and (right) Z250 (m), as estimated by GEFA for increasing number of regressors, as indicated in the left panels. The last row is for all regressors but using NP-KOE. Black contours indicate $10 \%$ significance; green lines denote the mean KE (from Kelly et al. 2010) and OE paths.

and the high-latitude low is weakened. This confirms that the response to the OE variability is NPO-like in autumn, resulting in a poleward shift of the westerly jet over the western North Pacific and a weakening over the North Atlantic (Fig. 9, top). It is similar to the response in FSKA, although the Bering Sea low is more elongated here, and the high over the subtropical Pacific narrower.

GEFA can be used to determine how the OE variability affects the surface turbulent heat flux. Since the heat flux responds rapidly, we use monthly anomalies and the heat flux lagging the OE index by 1 month, with $d=0$. The heat flux pattern is noisy and depends little on the number of regressors. As it is broadly similar in autumn and, albeit with larger amplitude, late winter, it is shown for SONDJF. As discussed in Gastineau and Frankignoul (2012), if the large-scale atmospheric response is substantial, the heat flux estimates may mix the heat flux feedback driven by the SST and the heat flux imprint of the atmospheric response. To remove the latter, we compute the time evolution of the SLP response pattern obtained similarly by GEFA at lag 1 by projecting it onto the concomitant SLP anomalies, thus primarily reflecting the natural variability of the SLP. Regressing the turbulent heat flux anomalies onto this time series provides the heat flux imprint of the atmospheric response, which is subtracted from the GEFA estimate, yielding the heat flux directly driven by the $\mathrm{OE}$ shifts, called "residual." The GEFA estimate (Fig. 10, top left) shows a strong heat loss over the OE SST footprint and weaker anomalies elsewhere. However, most of the latter are associated with the broader and smoother heat flux imprint of the atmospheric response that increases the westerlies, bringing colder air from Asia and increasing the oceanic heat loss (Fig. 10, top middle). Hence, the heat flux residual (Fig. 10, top right) is largely limited to the local OE SST footprint, acting 

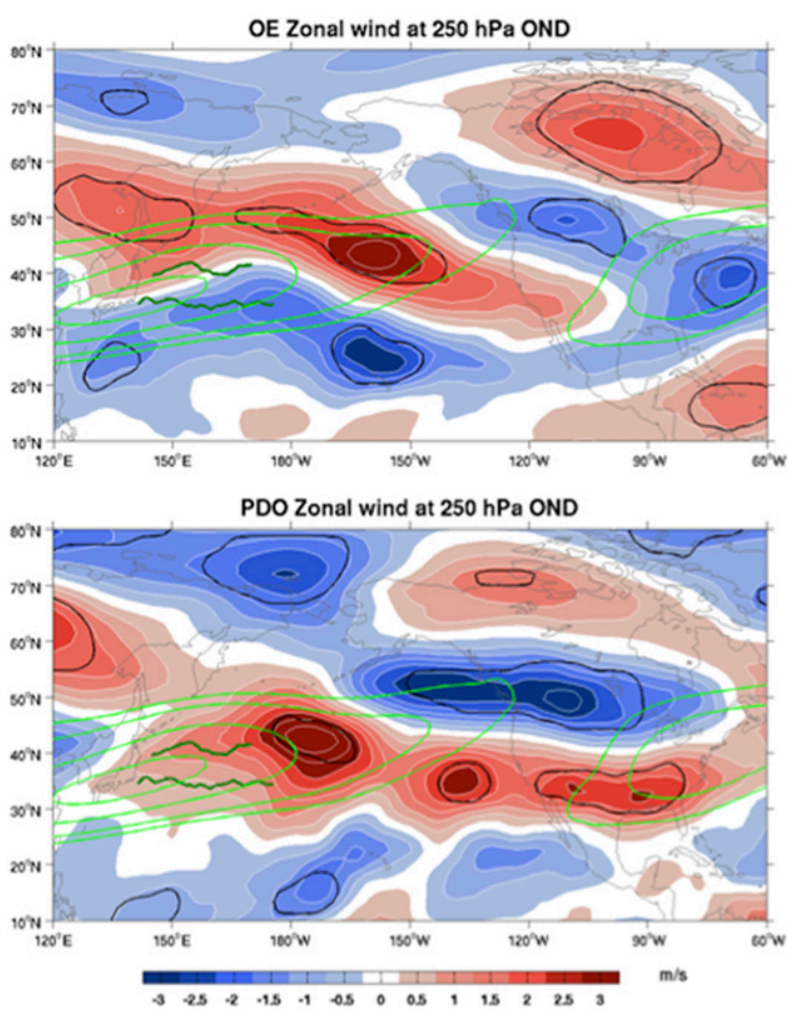

FIG. 9. OND response as estimated by GEFA of the zonal wind at $250 \mathrm{hPa}\left(\mathrm{m} \mathrm{s}^{-1}\right)$ to (top) the OE and (bottom) the PDO. Black contours indicate $10 \%$ significance and green lines denote the zonal wind climatology with contours at $25,30,40$, and $60 \mathrm{~m} \mathrm{~s}^{-1}$.

as a negative feedback of about $14 \mathrm{~W} \mathrm{~m}^{-2} \mathrm{~K}^{-1}$, consistent with the local heat flux feedback in Frankignoul and Kestenare (2002) and Park et al. (2005). A negative anomaly remains downstream of the OE path, near the weak PDO-like cooling in Fig. 7, but its amplitude and significance decrease if NP-KOE is used (not shown).

Since the Eady growth rate (EGR) anomaly driven by the OE shifts should reach its maximum amplitude in 2 or 3 weeks (Smirnov et al. 2015), GEFA is used similarly to estimate the EGR response at $850 \mathrm{hPa}$, but separately for each season. The EGR residual reflects the reduced baroclinicity caused by the weakened SST gradient south of the OE, but there is no significant EGR increase where the SST gradient is increased (Fig. 11). This primarily leads to a weakening and slight northward shift of the maximum baroclinicity; the EGR is also weakened in the northeastern North Pacific.

As the synoptic eddy activity is closely linked to the large-scale atmospheric patterns, its response is estimated using seasonal means, as for SLP and Z250. Although with very limited statistical significance, the meridional eddy heat flux and the storm-track activity are slightly reduced in the KOE region where the EGR was reduced and shifted northward; the storm track is intensified in the eastern Pacific (Fig. 11). Very similar results are found with NP-KOE. These estimates are noisy, but broadly consistent with the poleward shift of the westerly jet. The anomalous wave activity flux at $250 \mathrm{hPa}$, derived from the monthly geopotential height and temperature anomalies following Takaya and Nakamura (2001), suggests that there are two sources of wave activity, a noisy one near and upstream of the KOE region, and a larger one in the eastern Pacific, presumably linked to the shift in the storm tracks (supplemental Fig. 2, left).

As discussed in section 3, the atmospheric response to OE variability could not be estimated in DJF because of multicollinearity, but it is robust in FMA. The OE SST footprint is a broad warming along the mean $\mathrm{OE}$ path that becomes narrower when the PDO regressor is included (Fig. 12); there is also a significant cooling south of the Aleutians and a warming along the west coast of North America. However, with NP-KOE (Fig. 12, bottom), the $\mathrm{OE}$ warming is broader and the remote anomalies much less significant, so that the $\mathrm{OE}$ footprint is primarily local, as in ASO. The addition of regressors in GEFA affects little the estimated response patterns but increases their amplitude. The response primarily is a barotropic dipole, with a very strong and broad low over the Bering Sea that reaches $6 \mathrm{hPa}$ at sea level and $80 \mathrm{~m}$ at $250 \mathrm{hPa}$, and a weaker high around $30^{\circ} \mathrm{N}$, albeit only significant in the upper troposphere when all regressors are considered, with little change when NP$\mathrm{KOE}$ is used. Overall, the atmospheric response to the $\mathrm{OE}$ in late winter is not very different from that in autumn, but the SLP low over the Bering Sea is much broader and stronger, and there is no evidence of stationary wave propagation nor significant teleconnections (not shown). The estimated EGR response shows little links with the SST changes, and there is an eastward shift of the transient eddy activity, together with its reduction over the Bering Sea (not shown).

\section{c. Response to the KE variability}

In autumn, the response to the KE variability primarily is an equivalent barotropic tripolar pattern, with a ridge over the Sea of Okhotsk and over western Canada, and a trough in the Pacific side of the polar vortex (Fig. 7). It is similar to the ONDJ response found by partial regression in Révelard et al. (2016), except that the ridge is narrower and less extended eastward north of the KOE, which turns out to be due to the addition of the SIC regressor. See Révelard et al. (2016) for a discussion of main dynamics that control the atmospheric response.

In DJF, a stable KE state is associated with a warming of the eastern $\mathrm{KOE}$ region as in autumn, reflecting its 

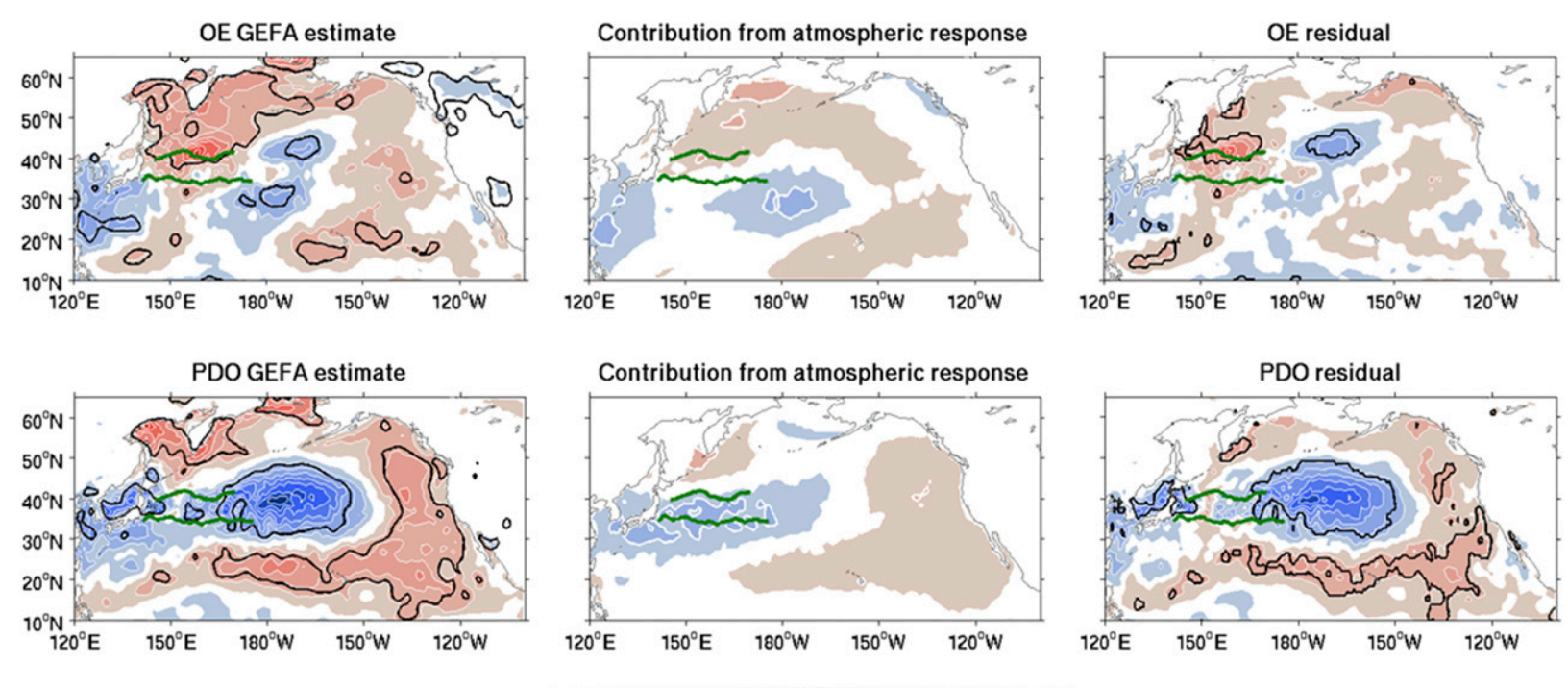

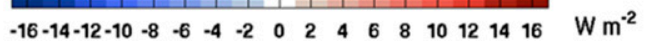

FIG. 10. Turbulent heat flux ( $\mathrm{W} \mathrm{m}^{-2}$, positive upward) response in SONDJF to the (upper row) OE and (bottom row) the PDO, as estimated by (left) GEFA, (middle) contribution from the atmospheric response, and (right) heat flux residual. Green lines denote the mean $\mathrm{KE}$ and $\mathrm{OE}$ paths, and black contours indicate $10 \%$ significance.

northward shift and enhanced advection, the decreased eddy activity off Japan (Qiu et al. 2014), and a cooling in the western subarctic that likely results from the atmospheric fluctuations that affect the KE on a short-time scale (Révelard et al. 2016). The estimated atmospheric response, shown in supplementary Fig. 1, is insensitive to the number of regressors, but it is small and lacks statistical significance, although it is similar to the partial regression of Révelard et al. (2016).

In FMA, the expected SST warming associated with the stable state of the KE is most clearly seen when only $\mathrm{KE}, \mathrm{OE}$, and TIP are considered, but it becomes increasingly small and noisy along the KE path when the PDO and NPGO regressors are added (Fig. 13), perhaps because the KE warming is more closely associated with the strengthening of the subtropical and subpolar gyres that covary with the NPGO (Ceballos et al. 2009). However, the SST signature is barely broader with NPKOE (Fig. 13, bottom). On the other hand, the estimated atmospheric response in the North Pacific is not sensitive to the changes in the KE SST footprint, and only the upper-tropospheric high over western Canada is $10 \%$ significant.

\section{d. Response to the (extratropical) $P D O$}

The robustness of the influence of the PDO in autumn is seen in Fig. 14. When used as a sole regressor, the PDO SST footprint includes tropical Pacific warming, as discussed in section 2, and the estimated response correspondingly mixes the response to extratropical and tropical forcing. Including the NPGO and TIP yields the typical SST anomaly associated with a positive phase of the PDO (Fig. 2), but the SST cooling near Japan is reduced when the OE is included, without further influence of the other regressors. Once the EN1 and EN2 have been included, the estimated atmospheric response to the positive phase of the PDO varies little with the number of regressors, except for a progressive strengthening of the Bering Sea low that reaches $4 \mathrm{hPa}$ at sea level and $40 \mathrm{~m}$ at $250 \mathrm{hPa}$ when the OE in included, resulting in a northwestward strengthening of the Aleutian low (Fig. 14). Although it is not very different from the NPO/WP-like response to the OE (Fig. 8), despite their negative correlation, all centers of action are slightly shifted, and the PDO strengthens the westerly jet over the eastern half of the United States, rather than weakening it (Fig. 9, bottom). Although noisy, the estimated response of the meridional eddy heat flux and the storm tracks suggest a strengthening and slight southward shift of the transient eddy activity in the central North Pacific (bottom panels in Fig. 15), broadly consistent with the southward shift of the meridional SST gradient in a positive PDO phase. Interestingly, the storm-track response to the PDO is broadly opposite to that caused by a northward OE shift, but for more significant signals in the central North Pacific. The turbulent heat flux driven by the PDO is only weakly affected by the large-scale atmospheric response (Fig. 10), and the heat flux residual (the PDO footprint) is strongest in the central and eastern Pacific, where it acts as a negative feedback of 10 to $16 \mathrm{~W} \mathrm{~m}^{-2} \mathrm{~K}^{-1}$, as found at large scales by Frankignoul and Kestenare (2002). Consistent 
a)

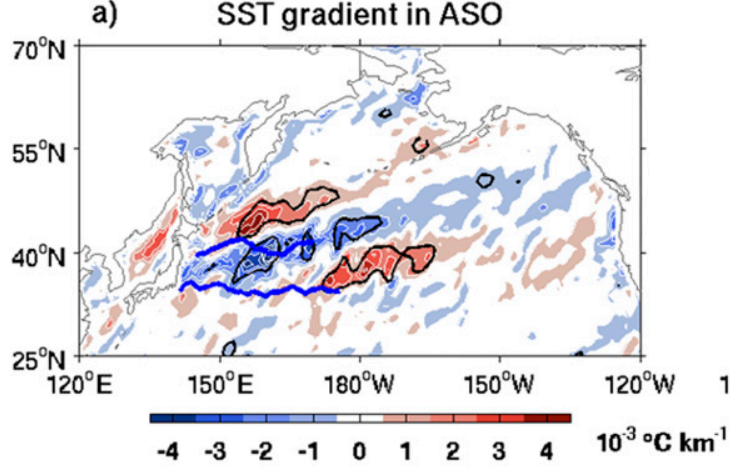

b) EGR at $850 \mathrm{hPa}$ residual in SON

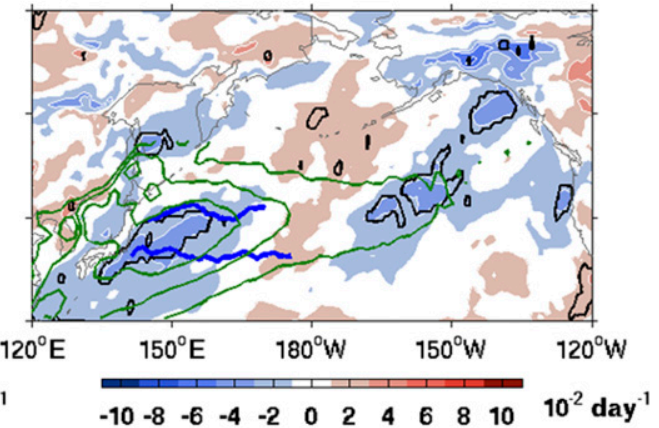

d) Storm track at $500 \mathrm{hPa}$ in OND

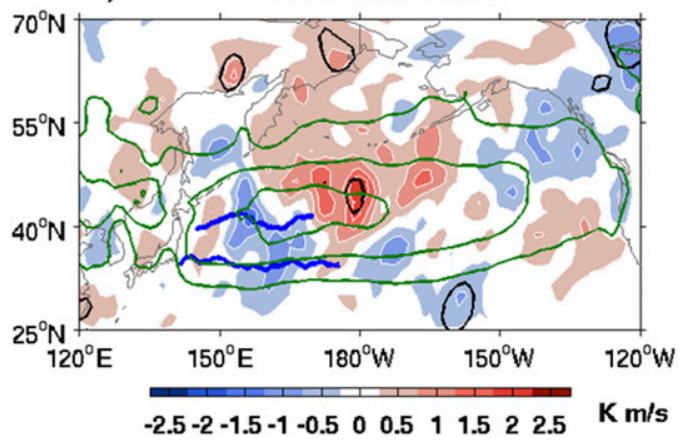

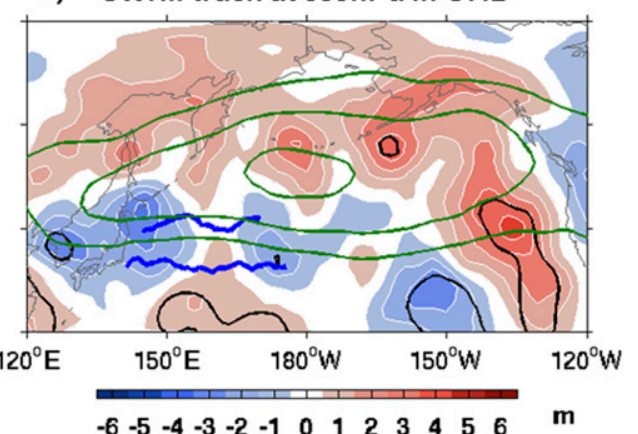

FIG. 11. (a) SST gradient footprint $\left(10^{-6} \mathrm{~K} \mathrm{~m}^{-1}\right)$ of the OE in ASO. Estimated response to the OE of (b) the EGR at $850 \mathrm{hPa}$ in SON $\left(10^{-2} \mathrm{day}^{-1}\right)$, (c) the meridional transient eddy heat flux at $850 \mathrm{hPa}\left(\mathrm{K} \mathrm{m} \mathrm{s}^{-1}\right)$, and (d) the storm track at $500 \mathrm{hPa}(\mathrm{m})$ in OND. Blue lines denote the mean KE and OE paths, and black contours indicate $10 \%$ significance. Green contours denote the climatology with contours at (b) 50,70, and $90 \times 10^{-2}$ day $^{-1}$, (c) 4, 7, and $10 \mathrm{~K} \mathrm{~m} \mathrm{~s}^{-1}$, and (d) 40,50 , and $60 \mathrm{~m}$.

with this anomalous heating, there is a significant source of wave activity at $250 \mathrm{hPa}$ in the central North Pacific, together with a weaker wave source in northeastern Asia (supplemental Fig. 2, right). Interestingly, the heat flux footprint of the PDO is sensitive to the inclusion of the $\mathrm{OE}$ regressor, as the downward heat flux is stronger in the west and weaker in the central North Pacific if OE is not taken into account (not shown). Figure 10 shows that, except to some extent in the central Pacific, the PDO heat flux footprint differs from that of a northward shift of the OE, and there is little signal in the western North Pacific, except near Japan. Since the two heat flux footprints only have opposite sign in this region and the PDO impact is largest in the central North Pacific, particularly in autumn, there is little reason to expect that the large-scale atmospheric response to the $\mathrm{OE}$ and the PDO will be of opposite sign, as could have been inferred from their SST signature in the KOE region.

Although using PDO-KOE is less appropriate for estimating PDO impacts than $\mathrm{OE}$ ones, it provides useful hints on the geographical origin of the PDO influence, since the SST cooling is strongly reduced and negligible west of $170^{\circ} \mathrm{E}$, while the warming along North
America is enhanced (Fig. 14, bottom row); however, tropical and extratropical warming are not as well separated. The heat flux residual (not shown) is similar to that in Fig. 10, but for slightly weaker negative values in the western and central North Pacific and stronger positive ones in the eastern North Pacific. As the estimated OND response to PDO-KOE is similar to that of the standard PDO, but mostly weaker and more confined to the North Pacific sector, much of the PDO influence in autumn seems to arise from SST in the central North Pacific.

The PDO SST footprint in OND and the estimated winter response in DJF (Fig. 16) depend very little on the number of regressors once EN1 and EN2 are included. Over the North Pacific, the upper-level response resembles a negative phase of the NPO. There is a strong westward tilt with height, suggesting baroclinicity: the SLP high over western Canada is found over the Bering Strait at $250 \mathrm{hPa}$, while the SLP low over the Sea of Okhotsk reinforces the Z250 low over Siberia, and the weak SLP low north of the Hawaiian Archipelago corresponds to the Z250 through in the subtropical North Pacific. In addition, there are strong barotropic 

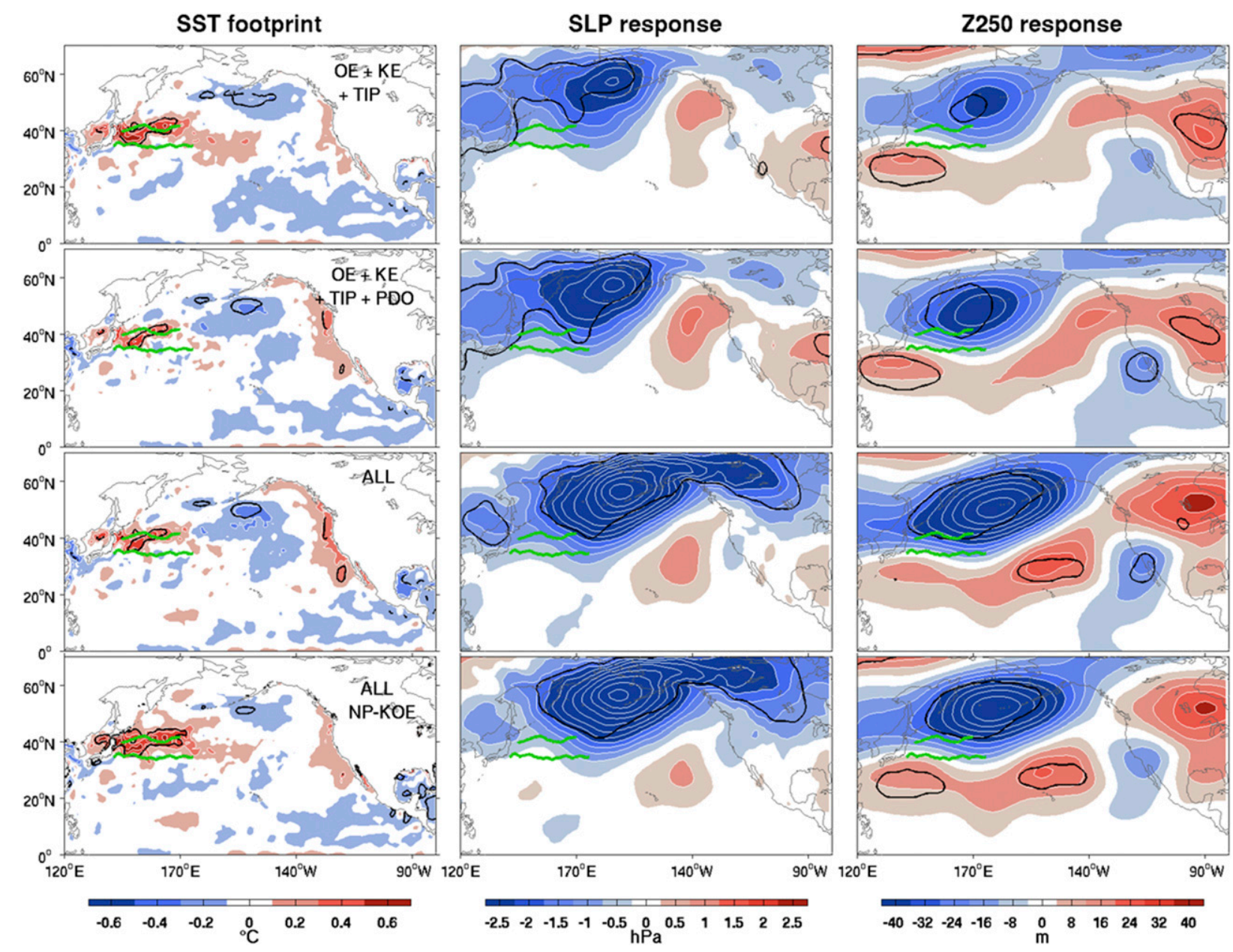

FIG. 12. As in Fig. 8, but for the OE SST footprint in DJF and the SLP and Z250 responses in FMA.

teleconnections over northern Siberia and the North Atlantic, where it resembles a negative phase of the NAO. However, recall that the OE is not included in GEFA in DJF. In this season, the PDO induces a southward shift of the region of maximum baroclinicity, consistent with the anomalous SST gradient, and a strengthening and southward shift of the storm track in the western North Pacific (upper panels in Fig. 15). Gan and $\mathrm{Wu}$ (2013) similarly found at low frequency that a positive phase of the PDO shifts the storm track southward, albeit without strengthening in the $\mathrm{KOE}$ region. The strong storm-track response in the western North Pacific may seem inconsistent with the weak heat flux anomaly there in Fig. 10. However, seasonal estimates indicate that the western North Pacific heat flux response is stronger in NDJ than in the other seasons, or when using OAFlux instead of ERA-Interim (supplemental Fig. 3). The North Pacific signal differs from the deepening of the Aleutian low found in winter by Liu et al. (2012), but this primarily reflects nonstationarity as discussed in section 5 , and the NAO teleconnection is similar.

The PDO SST footprint in DJF that drives the FMA atmospheric response varies little with an increasing number of regressors once EN1 is included in the multiple regression, although taking OE into account increases the eastern North Pacific warming and slightly reduces the KOE cooling, reflecting their strong anticorrelation ( $r=-0.5$; Fig. 17). In this season, including the TIP regressors only slightly alters the estimated atmospheric response (not shown), which only slightly intensifies as NAH and SIC are added (cf. the upper two rows in Fig. 17), until the OE is included (Fig. 17, third row). Indeed, the barotropic dipolar response in the North Pacific only becomes (weakly) significant when the $\mathrm{OE}$ is included. Interestingly, it strongly strengthens when using NP-KOE (Fig. 17, bottom panels), which more strongly reduces the KOE cooling while enhancing the southeastern warming. The response to PDO-KOE deepens and slightly shifts the Aleutian low northeastward, 

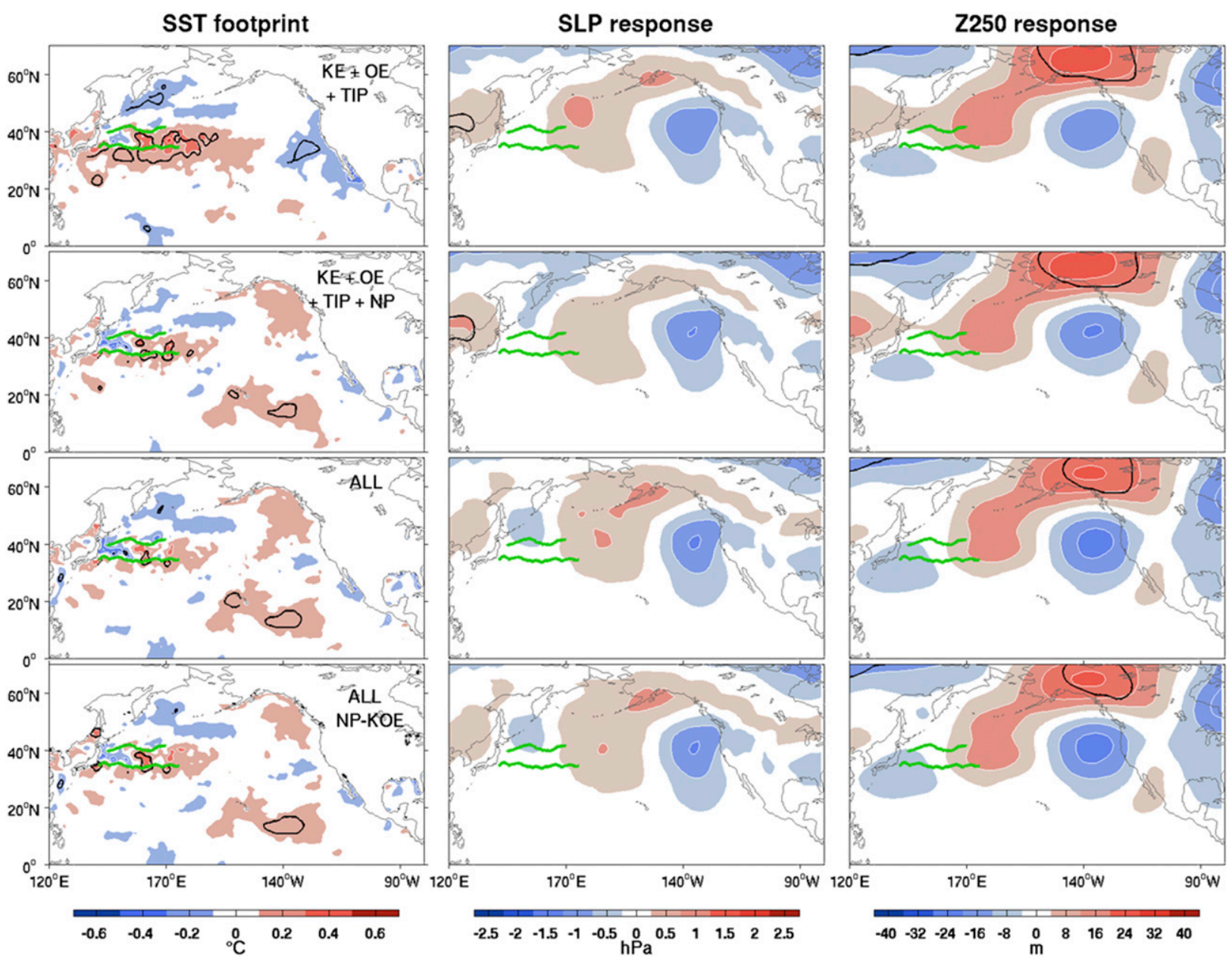

FIG. 13. (left) SST footprint (K) of the KE in DJF and GEFA response in FMA of (middle) SLP (hPa) and (right) Z250 (m) for an increasing number of regressors, as indicated. The last row is for all regressors but using NP-KOE. Black contours indicate $10 \%$ significance; green lines denote the mean KE and OE paths.

so that it is coarsely similar to the NPO or to the Pacific (P) pattern described by Hsu and Wallace (1985); correspondingly, the storm track is enhanced in the eastern North Pacific (Fig. 18), as in Lau (1988). The gradual changes of the responses to the PDO in Fig. 17 are consistent with the gradual removal of an interference with the response to the $\mathrm{OE}$, as a southward shift of the $\mathrm{OE}$ (cooling) drives a strong negative NPO-like response in late winter (Fig. 12, with opposite polarity), while the PDO drives a positive NPO-like response. Hence, the North Pacific response to the (extratropical) PDO seems more strongly influenced in late winter than in autumn by the western Pacific cooling, and it is only detected when the $\mathrm{OE}$ is taken into account, most clearly appearing when the PDO cooling in the KOE region is reduced by the use of NP-KOE. This suggests that the origin of the PDO influence on the atmosphere depends on the season. On the other hand, the upper-level dipole over Asia and the negative NAO-like teleconnection are always found.

\section{Summary and discussion}

The seasonal mean atmospheric response to the variability of the $\mathrm{OE}$, the $\mathrm{KE}$, and the PDO was investigated in the cold season during the period 19792014, using the multivariate GEFA (Liu et al. 2008), also taking into account the influence of the dominant SST and SIC anomaly modes. The response was investigated in OND, DJF, and FMA, and its robustness assessed by their sensitivity to an increasing number of oceanic modes. Although the SST anomalies associated with each single oceanic variable include remote anomalies and many cross-basin correspondences, reflecting the correlation between regressors, the multivariate approach was very efficient at confining the SST footprint of each regressor to its domain of definition. In particular, the ENSO footprints were confined to the equatorial band, and the PDO and NPGO restricted to their 

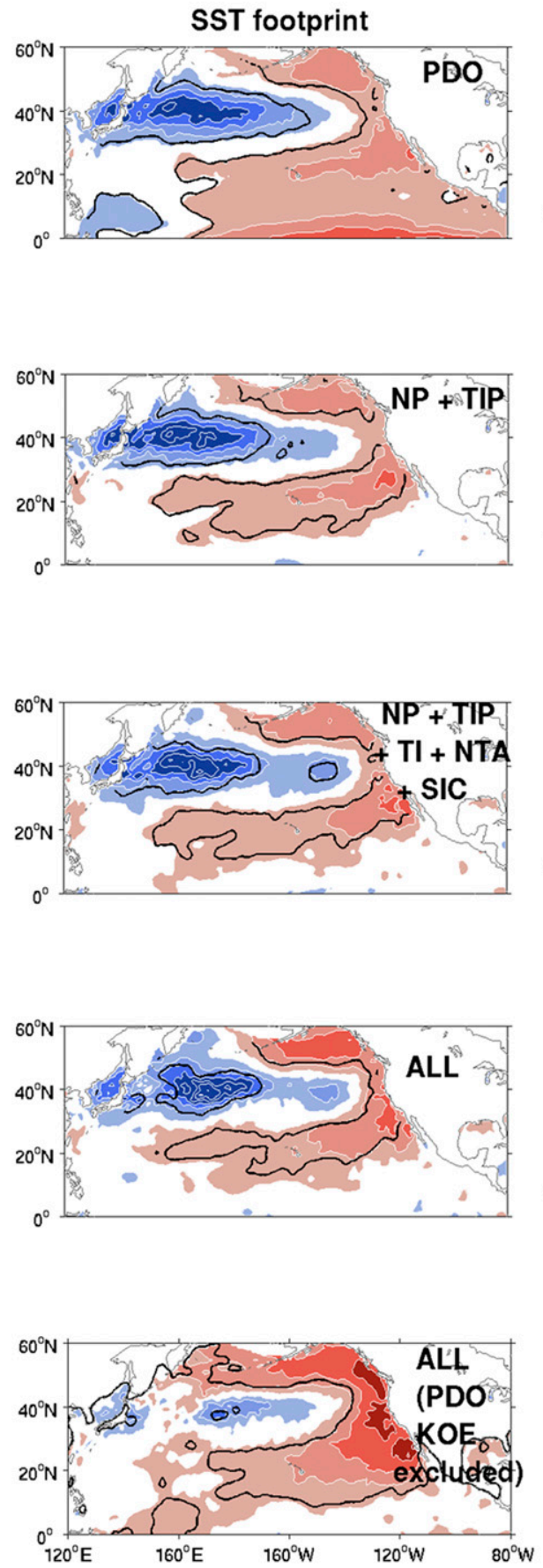

$\begin{array}{lllllllll}-0.8 & -0.6 & -0.4 & -0.2 & { }^{\circ} \mathrm{C} & 0.2 & 0.4 & 0.6 & 0.8\end{array}$

\section{SLP response}

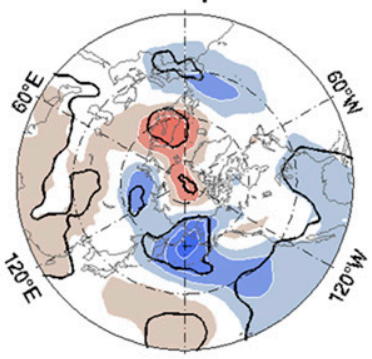

$\mathrm{Z250}$ response
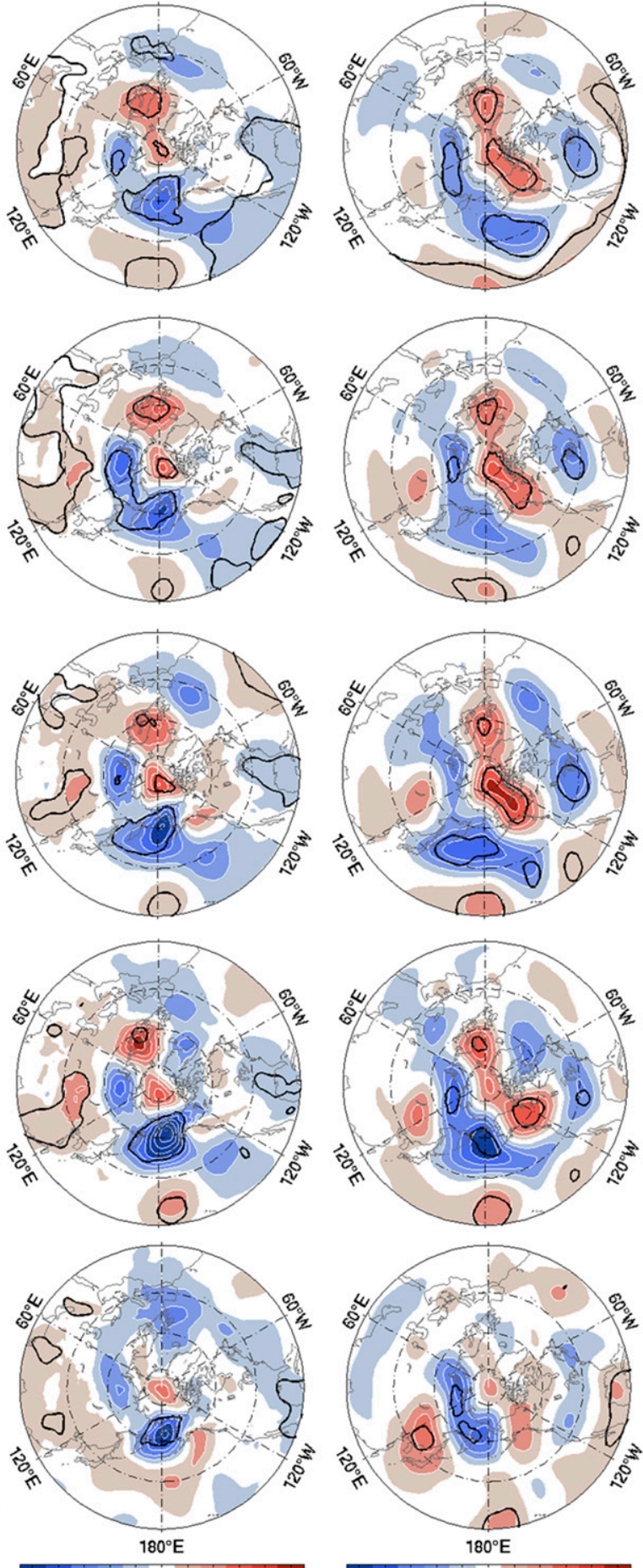

$-2.5-2-1.5-1-0.500 .511 .522 .5$ $\mathrm{hPa}$

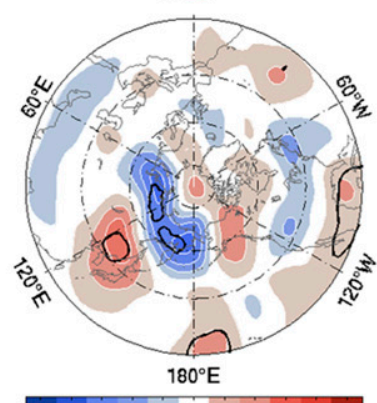

$-40-32-24-16-8 \quad 0 \quad 8 \quad 16243240$

$\mathrm{m}$

FIG. 14. (left) SST footprint (K) of the PDO in ASO and GEFA response in OND north of $20^{\circ} \mathrm{N}$ of (middle) SLP $(\mathrm{hPa})$ and (right) Z250 (m) for different sets of regressors, as indicated. Green lines denote the mean KE and OE paths; black contours indicate $10 \%$ significance. 
a) SST gradient in OND

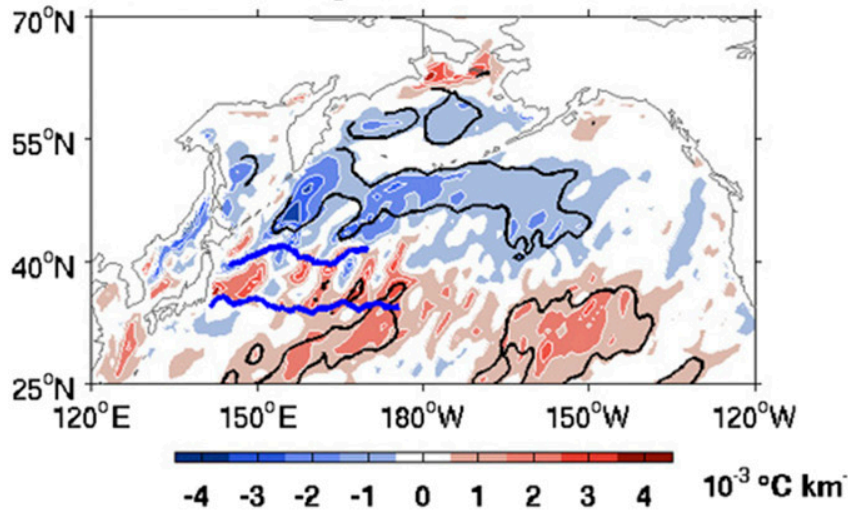

c) $\quad v^{\prime} T^{\prime}$ at $850 \mathrm{hPa}$ in DJF

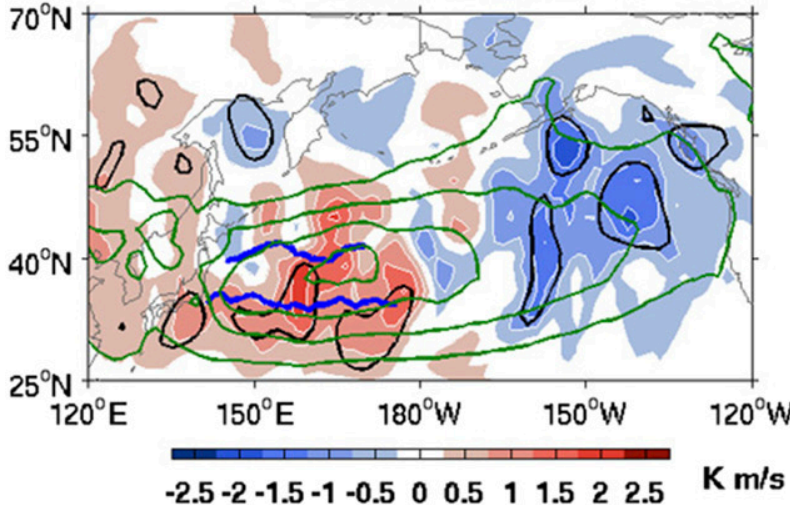

e) $\quad \mathrm{v}^{\prime} \mathrm{T}^{\prime}$ at $850 \mathrm{hPa}$ in OND

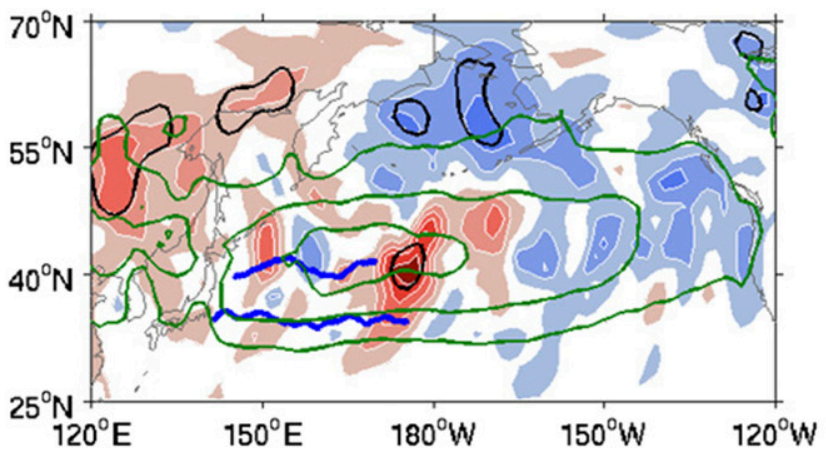

b) EGR at $850 \mathrm{hPa}$ residual in NDJ

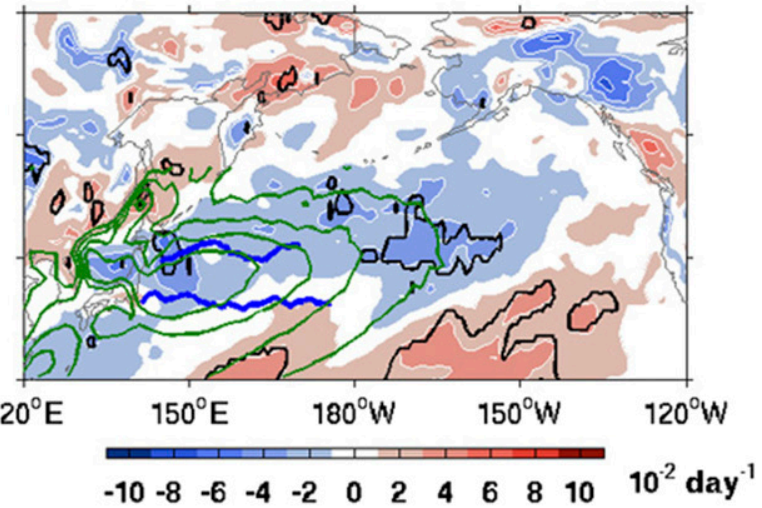

\section{d) Storm track at $500 \mathrm{hPa}$ in DJF}

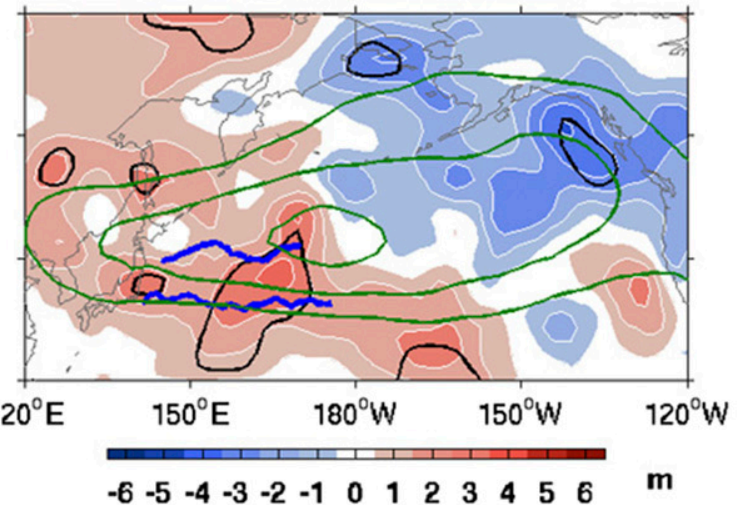

\section{f) Storm track at $500 \mathrm{hPa}$ in OND}

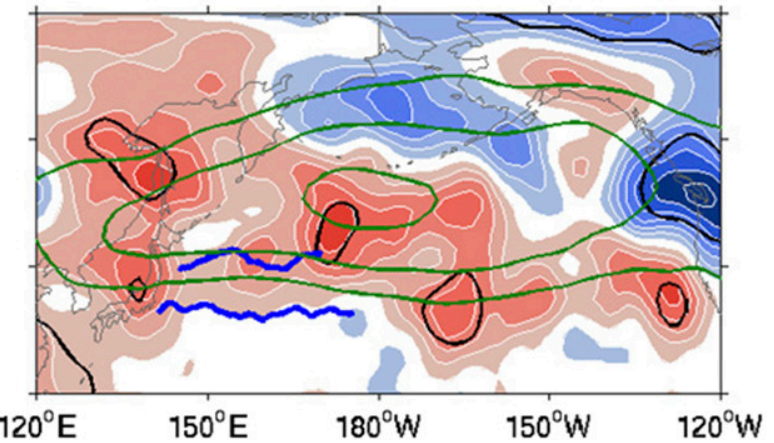

$\begin{array}{lllllllllllll}-2.5 & -2 & -1.5 & -1 & -0.5 & 0 & 0.5 & 1 & 1.5 & 2 & 2.5 & \mathrm{~K} \mathrm{~m} / \mathrm{s}\end{array}$

FIG. 15. (a) SST gradient footprint $\left(10^{-30} \mathrm{C} \mathrm{km}^{-1}\right)$ of the PDO in OND, and estimated response to the PDO of (b) the EGR at $850 \mathrm{hPa}$ in NDJ $\left(\mathrm{CI}=2 \times 10^{-2} \mathrm{day}^{-1}\right)$, (c) the meridional transient eddy heat flux at $850 \mathrm{hPa}\left(\mathrm{CI}=0.5 \mathrm{~K} \mathrm{~m} \mathrm{~s}^{-1}\right)$, and $(\mathrm{d})$ the storm track at $500 \mathrm{hPa}(\mathrm{CI}=1 \mathrm{~m})$ in DJF. Estimated response to the PDO of (e) the meridional transient eddy heat flux at $850 \mathrm{hPa}\left(\mathrm{CI}=0.5 \mathrm{~K} \mathrm{~m} \mathrm{~s}^{-1}\right)$ and (f) the storm track at $500 \mathrm{hPa}$ $(\mathrm{CI}=1 \mathrm{~m})$ in OND. Blue lines denote the mean $\mathrm{KE}$ and $\mathrm{OE}$ paths, and black contours indicate $10 \%$ significance. Green contours denote the corresponding season climatology with contours at (b) 55, 75, 95, and $115 \times 10^{-2}$ day $^{-1}$, (c) and (e) 4, 7, 10, and $13 \mathrm{~K} \mathrm{~m} \mathrm{~s}^{-1}$, and (d) and (f) 40, 50, and 60 m.

extratropical signatures. This is opposite to the transformation used by Chen and Wallace (2016), where the ENSO signal was limited to a narrower equatorial band and the PDO had the equatorial component that characterized its decadal variations. Our estimation of the atmospheric response to the PDO is to the extratropical part of the PDO.

In autumn, a northward shift of the $\mathrm{OE}$ is followed by an NPO-like signal, typically reaching $2 \mathrm{hPa}$ at sea level 


\section{SLP response}

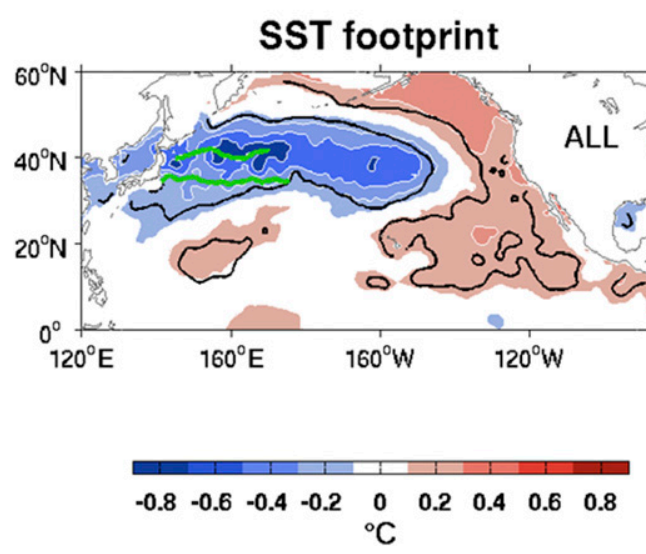

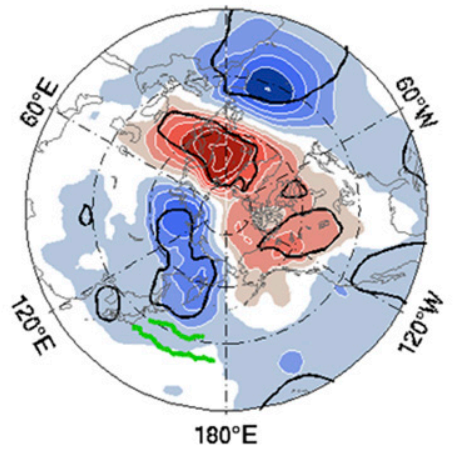

$-2.5-2-1.5-1-0.5 \quad 0 \quad 0.5111 .522 .5$

$\mathrm{hPa}$
Z250 response

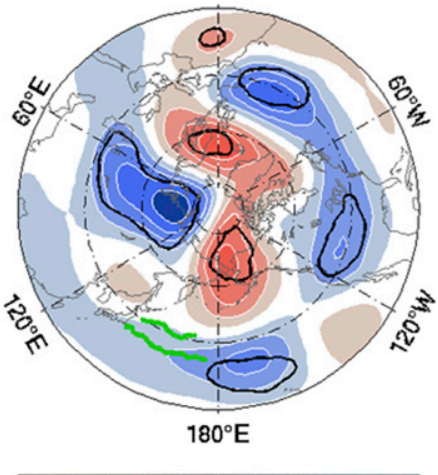

$-40-32-24-16-8 \quad 0 \quad 8 \quad 16243240$

$\mathrm{m}$

FIG. 16. As in Fig. 14, but for the SST footprint (K) of the PDO in OND, and SLP and Z250 in DJF.

and $30 \mathrm{~m}$ at $250 \mathrm{hPa}$, and a WP-like teleconnection pattern, similar to the response found by FSKA, using partial regression. Although noisy, the estimated responses of the EGR and the meridional eddy heat flux are broadly consistent with a northward shift of the maximum SST gradient, and in agreement with Rivière (2009), who showed that a more poleward baroclinicity favors anticyclonic wave-breaking events, leading to a poleward shift of the eddy-driven jet, while the stormtrack activity is enhanced in the eastern North Pacific. Multicollinearity prevented us from investigating the OE influence in winter, but a robust $O E$ influence is found in FMA. The response is broadly NPO-like, but with a strong low over the Bering Sea, typically reaching $6 \mathrm{hPa}$ at sea level and $80 \mathrm{~m}$ at $250 \mathrm{hPa}$, resulting in a northeastward strengthening of the Aleutian low. However, no clear link was found between the SST footprint and the EGR; hence how the OE variability influences the atmospheric circulation in late winter remains unclear. Since OE shifts and PDO are anticorrelated and both associated with large SST anomalies in the KOE region, we also used, instead of the PDO, a PDO-KOE index defined with the KOE region excluded, which is less correlated with the $\mathrm{OE}$ and has a much smaller cooling in the KOE. However, using PDO-KOE affected the response to the OE very little, confirming its robustness.

The response to the OE shifts differs from the highresolution response study of Smirnov et al. (2015), where a northward OE shift causes in DJFM a weakening of the Aleutian low. To investigate the response to the OE shifts, Taguchi et al. (2012) used an OE index based on monthly SST anomalies averaged in the subarctic frontal zone, which may not distinguish the OE from other SST modes, which in part motivated our study; from 1979 to 2014 their index is as well correlated with our OE index $(r=0.57)$ as with the PDO $(r=-0.6)$. The response of Taguchi et al. (2012) during the period 1959-2006 is PNA-like with a strong weakening of the Aleutian low in January (weaker in December), and a weaker strengthening in February. This strong seasonal dependence contrasts the broad similarity of the autumn and late winter response found here, albeit based on seasonal means. The January response in Taguchi et al. (2012) differs from our estimate in OND but has similarities with the response to a negative phase of the PDO in OND or DJF. Nonetheless, the response differences may reflect differences in the analysis period, as suggested by Taguchi et al. (2012) and discussed below. In addition, numerical simulations have stressed the sensitivity of the atmospheric response to small changes in the background mean state, in particular between January and February (Peng et al. 1997; Peng and Whitaker 1999; Brayshaw et al. 2008; Taguchi et al. 2012), which could affect results based on seasonal averages. Interestingly, the strengthening of the Aleutian low that they found in February is consistent with our FMA response to the OE.

A robust barotropic response to the KE variability is found in autumn, consistent with the partial regression analysis of Révelard et al. (2016), who discussed it in detail. Despite the broad KE SST footprint in the KOE region, no significant atmospheric response is found in winter. In late winter, the KE SST footprint becomes small and noisy along the KE path when the PDO and NPGO are added in GEFA. Hence, the estimated response might reflect other forcing, such as snow cover, the East Asian winter monsoon, or Southern Hemisphere forcing that also impacts or covaries with the KE path. 


\section{SLP response}

SST footprint
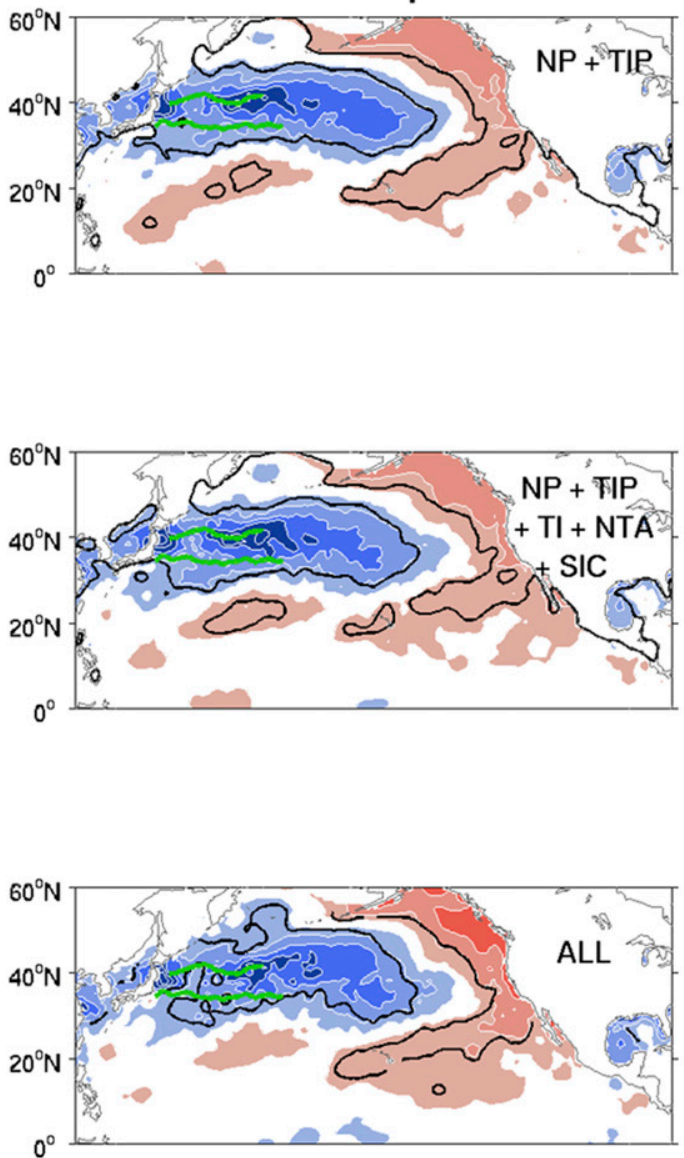

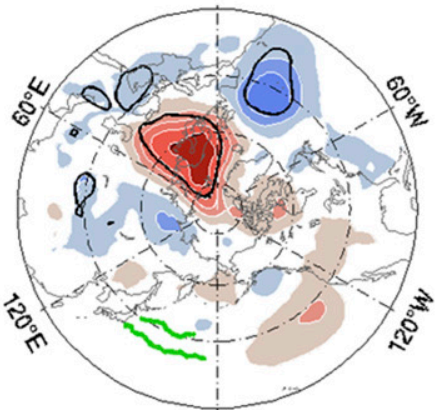

Z250 response
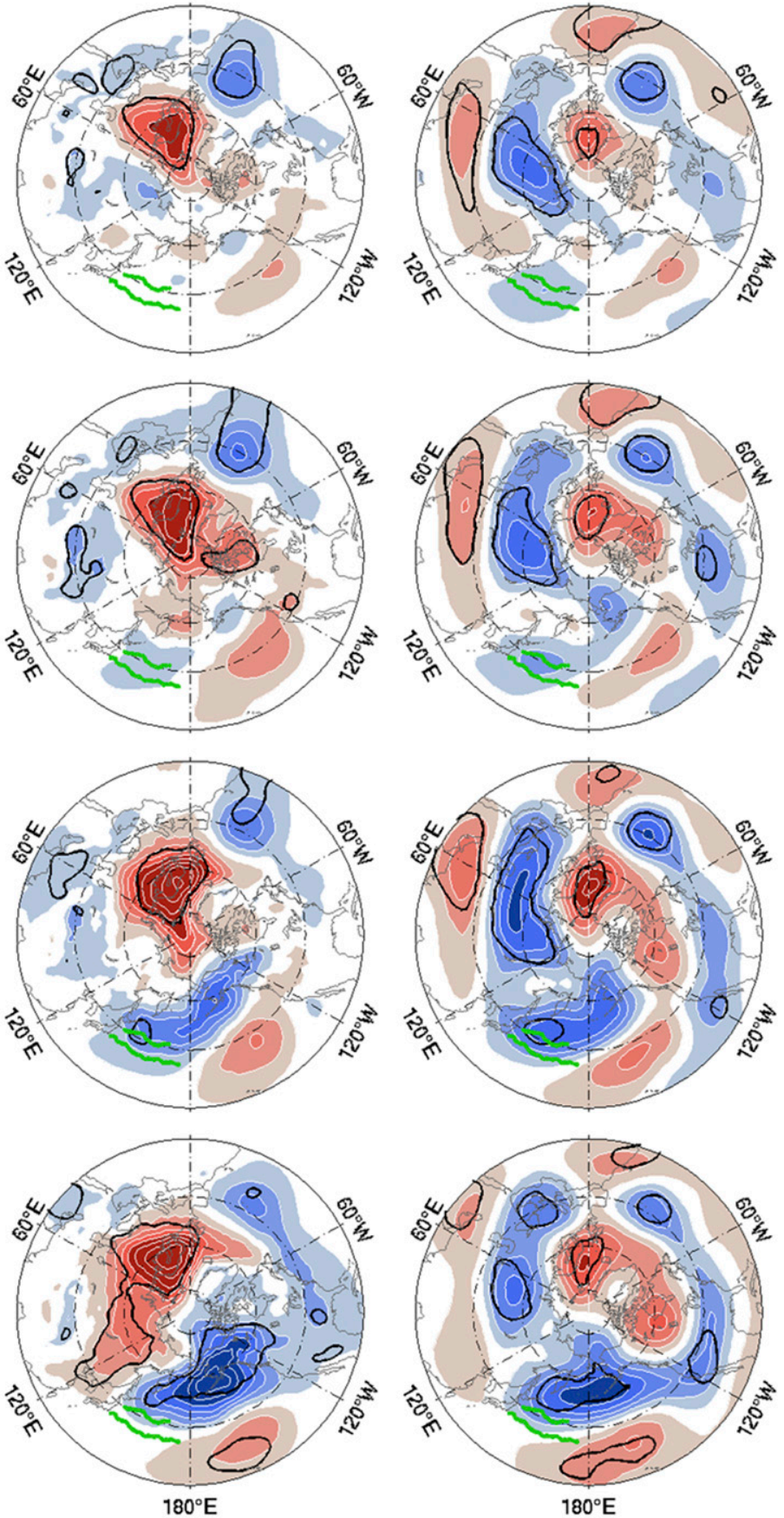

$-40-32-24-16-8 \quad 0 \quad 8 \quad 162432 \quad 40$

$\mathrm{m}$

FIG. 17. As in Fig. 14, but for the SST signature in DJF and the SLP and Z250 response to the PDO in FMA.

A positive phase of the PDO primarily drives a downward heat flux in the central North Pacific, which is strongest when the OE is taken into account in GEFA, and acts as a negative feedback of 10 to $16 \mathrm{~W} \mathrm{~m}^{-2} \mathrm{~K}^{-1}$, consistent with Frankignoul and Kestenare (2002). The PDO is followed in autumn by a significant source of wave activity in the central North Pacific and a northward strengthening of the Aleutian low, with an 


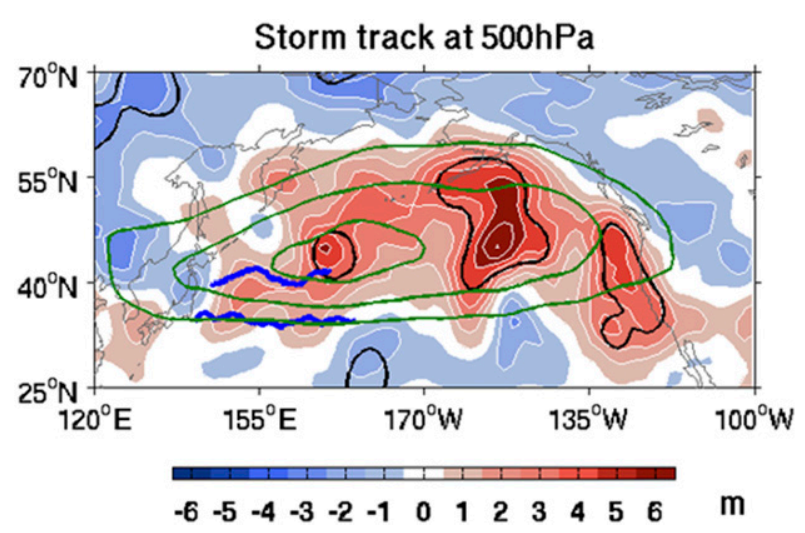

FIG. 18. Estimated response of the storm track at $500 \mathrm{hPa}(\mathrm{m})$ in FMA to PDO-KOE. Blue lines denote the mean KE and OE paths, and black contours indicate $10 \%$ significance. Green contours denote the corresponding season climatology with contours at 40, 50, and $60 \mathrm{~m}$.

anomalous low over the Bering Sea typically reaching $4 \mathrm{hPa}$ at sea level and $40 \mathrm{~m}$ at $250 \mathrm{hPa}$. This strengthens the westerly jet in the central Pacific and shifts it southward over North America. Although noisy, the response of the meridional eddy heat flux and the storm tracks indicates a strengthening and slight southward shift of the transient eddy activity in the central North Pacific, broadly consistent with the southward shift of the meridional SST gradient in a positive PDO phase. The response to PDO-KOE is weaker and more confined to the North Pacific sector, suggesting that much of the PDO influence arises in autumn from SST in the central and eastern North Pacific. It might seem counterintuitive that broadscale SST anomalies in a region where the atmospheric forcing is dominant (Smirnov et al. 2014) could have an impact on the atmosphere comparable to those in the KOE region, which are largely driven by ocean dynamics. However, the heat flux footprint of existing SST anomalies does not depend on the way they were generated, as discussed in Frankignoul et al. (1998). The same should hold for the large-scale response to existing SST anomalies.

In winter, the PDO has a larger heat flux imprint in the western North Pacific, and it shifts the maximum baroclinicity and the storm track southward, as in Gan and $\mathrm{Wu}$ (2013). The upper-tropospheric response resembles a negative NPO, albeit strongly tilting westward with height, suggesting baroclinicity, with large barotropic teleconnections and a negative NAO-like signal in the North Atlantic. However, the OE was not included in GEFA in this season. In late winter, the negative NAO-like teleconnection remains, but the North Pacific response resembles a positive NPO, or the P pattern (Hsu and Wallace 1985; Lau 1988).
However, this response interferes negatively with the negative NPO-like response to a southward shift of the OE (PDO and OE are anticorrelated), and it only becomes significant when the OE regressor is included in GEFA, strengthening when using NP-KOE. This suggests that the western North Pacific cooling associated with the PDO has a stronger impact in this season. Interestingly, in winter the response to the (extratropical) PDO has similar amplitude to the response to EN1, both at $250 \mathrm{hPa}$ (supplemental Fig. 1) and at sea level (not shown). Hence, both tropical and extratropical components of the PDO significantly influence the extratropical atmospheric circulation.

Except perhaps in late winter, the response to the PDO differs from the GEFA estimates of Wen et al. (2010), who considered all the months of the year from 1958 to 2007, and Liu et al. (2012), who estimated seasonal response during the period 1948-2010, although the negative NAO-like teleconnection is similar. They found a strengthening of the Aleutian low, whereas our OND and FMA results suggest a northward strengthening of the Aleutian low. In DJF, the differences are even larger, as we find a negative NPO-like response. However, this primarily reflects nonstationarity (Fig. 19). Indeed, using the NCEP-NCAR reanalysis (Kalnay et al. 1996) from 1958 to 1977 and nine SST regressors (lacking sufficiently reliable data for KE, OE, and SIC), our estimated DJF response to the PDO is a strong strengthening of the Aleutian low, similar to that in Liu et al. (2012) or obtained by using GEFA as they did with a lag of 1 month and $d=0$ (Fig. 19, top). The Z250 response during the period 1979-2014 (Fig. 19, bottom) is nearly opposite and weaker, and barely significant at lag 1, presumably because the response has not reached large enough amplitude to be detected (section 3 ). The strong nonstationarity of the atmospheric response to the PDO is likely due to the changes in the mean state of the North Pacific circulation during the 1976-77 climate shift, which led to a deeper and eastward shifted Aleutian low (Trenberth and Hurrell 1994), in part motivating our choice of considering the 1979-2014 period. On the other hand, the response to EN1 remains broadly similar from 1958 to 1977. Pak et al. (2014) detected another North Pacific climate shift in 1988, with strong changes in the relation between the NPO and the East Asian winter monsoon attributed to the weakening of the Siberian high. Hence, the atmospheric response to North Pacific forcing might also differ before and after 1988. This should be investigated, but with more limited samples, GEFA may not be optimal.

In summary, the multivariate analysis is quite efficient in separating SST footprints and estimating large-scale 


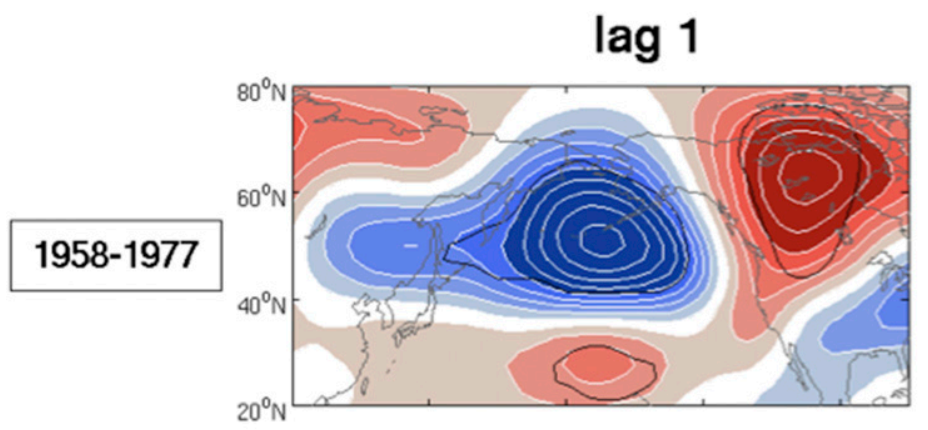

$\operatorname{lag} 3$

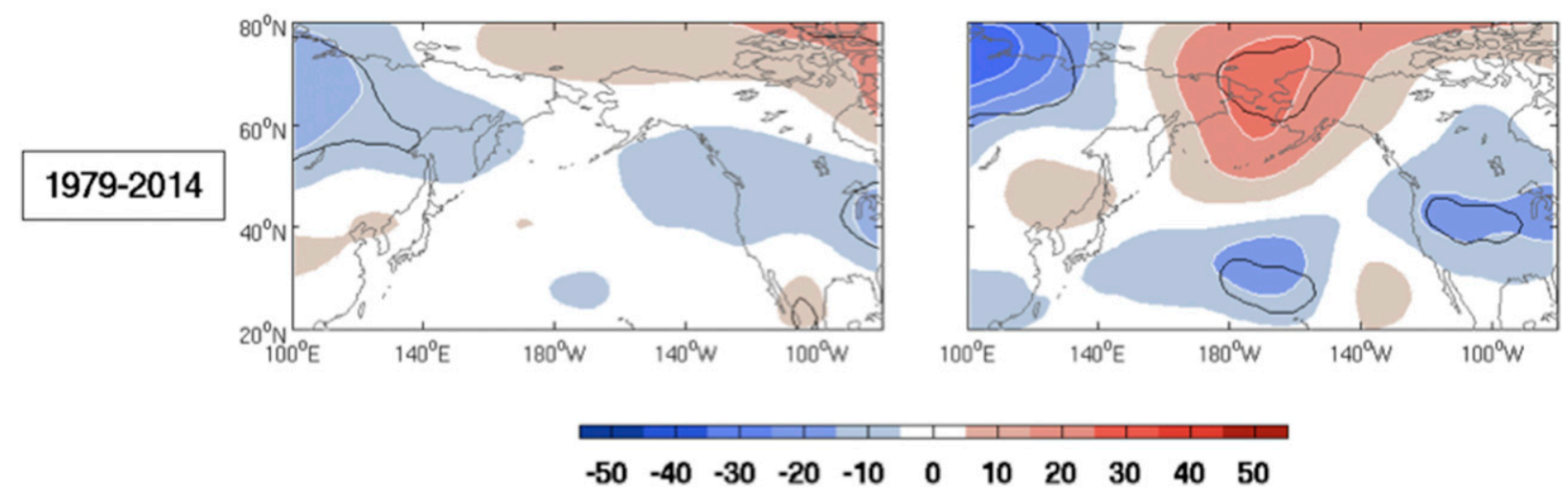

FIG. 19. DJF response of the geopotential height at $250 \mathrm{hPa}$ to the PDO as estimated by GEFA at a lag of (left) 1 month using monthly data and (right) 3 months using seasonal means in (top) 1958-77 and (bottom) 1979-2014.

atmospheric responses. The explained seasonal variance (adjusted $r^{2}$ ) is large in the tropics, but limited north of $30^{\circ} \mathrm{N}$, only exceeding $25 \%$ in a few regions, albeit with a substantial contribution of the extratropical regressors. However, the method has limitations, as GEFA is less effective with noisier variables like the EGR or the transient eddy activity, and no significant extratropical signal in vertical wind and precipitation could be extracted. In addition, separately considering the warm and cold phases of the different regressors led to much less confined SST footprints, hence asymmetries in the responses could not be investigated, even though asymmetries are found in ENSO teleconnections (Hoerling et al. 1997; Straus and Shukla 2002), the response to the KE (Révelard et al. 2016), and numerical response studies (e.g., Seo et al. 2014).

Acknowledgments. This research has received funding from the European Union 7th Framework Program (FP7 2007-2013) under Grant Agreement 308299 (NACLIM) and from NSF Grants AGS CLD 1035423 and OCE PO 1242989. We thank the reviewers for their thoughtful and constructive comments.

\section{REFERENCES}

Alexander, M. A., I. Bladé, M. Newman, J. R. Lanzante, N.-C. Lau, and J. D. Scott, 2002: The atmospheric bridge: The influence of ENSO teleconnections on air-sea interaction over the global oceans. J. Climate, 15, 2205-2231, https://doi.org/10.1175/15200442(2002)015<2205:TABTIO >2.0.CO;2.

Ashok, K., S. K. Behera, S. A. Rao, H. Weng, and T. Yamagata, 2007: El Niño Modoki and its possible teleconnection. J. Geophys. Res., 112, C11007, https://doi.org/10.1029/2006JC003798.

Blackmon, M. L., and N.-C. Lau, 1980: Regional characteristics of the Northern Hemisphere wintertime circulation: A comparison of the simulation of a GFDL general circulation model with observations. J. Atmos. Sci., 37, 497-514, https://doi.org/ 10.1175/1520-0469(1980)037<0497:RCOTNH >2.0.CO;2.

Bond, N. A., J. E. Overland, M. Spillane, and P. Stabeno, 2003: Recent shifts in the state of the North Pacific. Geophys. Res. Lett., 30, 2183, https://doi.org/10.1029/2003GL018597.

Brayshaw, D. J., B. J. Hoskins, and M. Blackburn, 2008: The stormtrack response to idealized SST perturbations in an aquaplanet GCM. J. Atmos. Sci., 65, 2842-2860, https://doi.org/ 10.1175/2008JAS2657.1.

Ceballos, L. I., E. Di Lorenzo, C. D. Hoyos, N. Schneider, and B. Taguchi, 2009: North Pacific Gyre Oscillation synchronizes climate fluctuations in the eastern and western boundary systems. J. Climate, 22, 5163-5174, https://doi.org/10.1175/2009JCLI2848.1.

Chen, X., and J. M. Wallace, 2016: Orthogonal PDO and ENSO indices. J. Climate, 29, 3883-3892, https://doi.org/10.1175/ JCLI-D-15-0684.1. 
Cheng, X., G. Nitsche, and J. M. Wallace, 1995: Robustness of lowfrequency circulation patterns derived from EOF and rotated EOF analysis. J. Climate, 8, 1709-1713, https://doi.org/10.1175/ 1520-0442(1995)008<1709:ROLFCP $>2.0 . C O ; 2$.

Comiso, J. C., 2000: Bootstrap sea ice concentrations from Nimbus7 SMMR and DMSP SSM/I-SSMIS, version 2 (updated 2012). National Snow and Ice Data Center Distributed Active Archive Center, accessed 4 January 2016, https://doi.org/10.5067/ J6JQLS9EJ5HU.

Czaja, A., and C. Frankignoul, 2002: Observed impact of Atlantic SST anomalies on the North Atlantic Oscillation. J. Climate, 15, 606-623, https://doi.org/10.1175/1520-0442(2002)015<0606: OIOASA $>2.0 . \mathrm{CO} ; 2$.

Dai, A., 2013: The influence of the inter-decadal Pacific oscillation on US precipitation during 1923-2010. Climate Dyn., 41, 633646, https://doi.org/10.1007/s00382-012-1446-5.

Davis, R. E., 1976: Predictability of sea surface temperature and sea level pressure anomalies over the North Pacific Ocean. J. Phys. Oceanogr., 6, 249-266, https://doi.org/10.1175/ 1520-0485(1976)006<0249:POSSTA >2.0.CO;2.

Dee, D. P., and Coauthors, 2011: The ERA-Interim reanalysis: Configuration and performance of the data assimilation system. Quart. J. Roy. Meteor. Soc., 137, 553-597, https://doi.org/ 10.1002/qj.828.

Deser, C., R. A. Tomas, and S. Peng, 2007: The transient atmospheric circulation response to North Atlantic SST and sea ice anomalies. J. Climate, 20, 4751-4767, https://doi.org/10.1175/ JCLI4278.1.

Di Lorenzo, E., and Coauthors, 2008: North Pacific Gyre Oscillation links ocean climate and ecosystem change. Geophys. Res. Lett., 35, L08607, https://doi.org/10.1029/2007GL032838.

Dong, B., and A. Dai, 2015: The influence of the interdecadal Pacific oscillation on temperature and precipitation over the globe. Climate Dyn., 45, 2667-2681, https://doi.org/10.1007/s00382-015-2500-x.

Ferreira, D., and C. Frankignoul, 2005: The transient atmospheric response to midlatitude SST anomalies. J. Climate, 18, 10491067, https://doi.org/10.1175/JCLI-3313.1.

Frankignoul, C., 1999: A cautionary note on the use of statistical atmospheric models in the middle latitudes: Comments on "Decadal variability in the North Pacific as simulated by a hybrid coupled model." J. Climate, 12, 1871-1872, https:// doi.org/10.1175/1520-0442(1999)012<1871:ACNOTU>2.0.CO;2. - and K. Hasselmann, 1977: Stochastic climate models. Part II: Application to sea-surface temperature anomalies and thermocline variability. Tellus, 29 (4), 289-305, https://doi.org/ 10.3402/tellusa.v29i4.11362.

—_, and E. Kestenare, 2002: The surface heat flux feedback. Part I: Estimates from observations in the Atlantic and the North Pacific. Climate Dyn., 19, 633-647, https://doi.org/10.1007/ s00382-002-0252-x.

— , and - 2005: Air-sea interactions in the tropical Atlantic: A view based on lagged rotated maximum covariance analysis. J. Climate, 18, 3874-3890, https://doi.org/10.1175/ JCLI3498.1.

_ SST anomalies on the atmospheric circulation. J. Climate, 20, 592-606, https://doi.org/10.1175/JCLI4021.1.

— - A. Czaja, and B. L'Heveder, 1998: Air-sea feedback in the North Atlantic and surface boundary conditions for ocean models. J. Climate, 11, 2310-2324, https://doi.org/10.1175/ 1520-0442(1998)011<2310:ASFITN>2.0.CO;2.

—, N. Sennéchael, Y.-O. Kwon, and M. A. Alexander, 2011: Influence of the meridional shifts of the Kuroshio and the Oyashio
Extensions on the atmospheric circulation. J. Climate, 24, 762777, https://doi.org/10.1175/2010JCLI3731.1.

,$- \ldots$, and P. Cauchy, 2014: Observed atmospheric response to cold season sea ice variability in the Arctic. J. Climate, 27, 1243-1254, https://doi.org/10.1175/JCLI-D-13-00189.1.

Gan, B., and L. Wu, 2012: Modulation of atmospheric response to North Pacific SST anomalies under global warming: A statistical assessment. J. Climate, 25, 6554-6566, https://doi.org/ 10.1175/JCLI-D-11-00493.1.

— wintertime storm tracks and sea surface temperature in the North Pacific. J. Climate, 26, 6123-6136, https://doi.org/ 10.1175/JCLI-D-12-00724.1.

García-Serrano, J., C. Frankignoul, G. Gastineau, and A. de la Cámara, 2015: On the predictability of the winter Euro-Atlantic climate: Lagged influence of autumn Arctic sea ice. J. Climate, 28, 5195-5216, https://doi.org/10.1175/JCLI-D-14-00472.1.

Gastineau, G., and C. Frankignoul, 2012: Cold-season atmospheric response to the natural variability of the Atlantic meridional overturning circulation. Climate Dyn., 39, 37-57, https://doi.org/ 10.1007/s00382-011-1109-y.

Haarsma, R. J., and W. Hazeleger, 2007: Extratropical atmospheric response to equatorial Atlantic cold tongue anomalies. J. Climate, 20, 2076-2091, https://doi.org/10.1175/JCLI4130.1.

Hoerling, M. P., A. Kumar, and M. Zhong, 1997: El Niño, La Niña, and the nonlinearity of their teleconnections. J. Climate, 10, 1769-1786, https://doi.org/10.1175/1520-0442(1997)010<1769: ENOLNA $>2.0 . \mathrm{CO} ; 2$

—, J. W. Hurrell, T. Xu, G. T. Bates, and A. S. Phillips, 2004: Twentieth century North Atlantic climate change. Part II: Understanding the effect of Indian Ocean warming. Climate Dyn., 23, 391-405, https://doi.org/10.1007/s00382-004-0433-x.

Horel, J. D., and J. M. Wallace, 1981: Planetary-scale atmospheric phenomena associated with the Southern Oscillation. Mon. Wea. Rev., 109, 813-829, https://doi.org/10.1175/ 1520-0493(1981)109<0813:PSAPAW >2.0.CO;2.

Hsu, H.-H., and J. M. Wallace, 1985: Vertical structure of wintertime teleconnection patterns. J. Atmos. Sci., 42, 1693-1710, https:// doi.org/10.1175/1520-0469(1985)042<1693:VSOWTP>2.0.CO;2.

Joyce, T. M., Y.-O. Kwon, and L. Yu, 2009: On the relationship between synoptic wintertime atmospheric variability and path shifts in the Gulf Stream and the Kuroshio Extension. J. Climate, 22, 3177-3192, https://doi.org/10.1175/2008JCLI2690.1.

Judge, G. G., R. C. Hill, W. E. Griffiths, H. Lütkepohl, and T.- C. Lee, 1988: Introduction to the Theory and Practice of Econometrics. 2nd ed. John Wiley and Sons, 1056 pp.

Kalnay, E., and Coauthors, 1996: The NCEP/NCAR 40-Year Reanalysis Project. Bull. Amer. Meteor. Soc., 77, 437-471, https:// doi.org/10.1175/1520-0477(1996)077<0437:TNYRP>2.0.CO;2.

Kelly, K. A., R. J. Small, R. M. Samelson, B. Qiu, T. M. Joyce, Y.- O. Kwon, and M. F. Cronin, 2010: Western boundary currents and frontal air-sea interaction: Gulf Stream and Kuroshio Extension. J. Climate, 23, 5644-5667, https://doi.org/ 10.1175/2010JCLI3346.1.

Kendall, M. G., 1946: The Advanced Theory of Statistics. Charles Griffin and Co., 521 pp.

Kwon, Y.-O., and C. Deser, 2007: North Pacific decadal variability in the Community Climate System Model version 2. J. Climate, 20, 2416-2433, https://doi.org/10.1175/JCLI4103.1. , and T. M. Joyce, 2013: Northern Hemisphere winter atmospheric transient eddy heat fluxes and the Gulf Stream and Kuroshio-Oyashio Extension variability. J. Climate, 26, 98399859, https://doi.org/10.1175/JCLI-D-12-00647.1. 
- C. Deser, and C. Cassou, 2011: Coupled atmosphere - mixed layer ocean response to ocean heat flux convergence along the Kuroshio Current Extension. Climate Dyn., 36, 2295-2312, https://doi.org/10.1007/s00382-010-0764-8.

Lau, N.-C., 1988: Variability of the observed midlatitude storm tracks in relation to low-frequency changes in the circulation pattern. J. Atmos. Sci., 45, 2718-2743, https://doi.org/10.1175/ 1520-0469(1988)045<2718:VOTOMS $>2.0 . C O ; 2$

_ and M. J. Nath, 1996: The role of the "atmospheric bridge" in linking tropical Pacific ENSO events to extratropical SST anomalies. J. Climate, 9, 2036-2057, https://doi.org/10.1175/ 1520-0442(1996)009<2036:TROTBI >2.0.CO;2.

- A. Leetmaa, M. J. Nath, and H.-L. Wang, 2005: Influences of ENSO-induced Indo-western Pacific SST anomalies on extratropical atmospheric variability during the boreal summer J. Climate, 18, 2922-2942, https://doi.org/10.1175/JCLI3445.1.

Linkin, M. E., and S. Nigam, 2008: The North Pacific Oscillationwest Pacific teleconnection pattern: Mature-phase structure and winter impacts. J. Climate, 21, 1979-1997, https://doi.org/ 10.1175/2007JCLI2048.1.

Liu, Q., N. Wen, and Z. Liu, 2006: An observational study of the impact of the North Pacific SST on the atmosphere. Geophys. Res. Lett., 33, L18611, https://doi.org/10.1029/2006GL026082.

Liu, Z., and L. Wu, 2004: Atmospheric response to North Pacific SST: The role of ocean-atmosphere coupling. J. Climate, 17 1859-1882, https://doi.org/10.1175/1520-0442(2004)017<1859: ARTNPS $>2.0$.CO;2.

- N. Nen, and Y. Liu, 2008: On the assessment of nonlocal climate feedback. Part I: The generalized equilibrium feedback assessment. J. Climate, 21, 134-148, https://doi.org/ 10.1175/2007JCLI1826.1.

_ L. Fan, S.-I. Shin, and Q. Liu, 2012: Assessing atmospheric response to surface forcing in the observations. Part II: Cross validation of seasonal response using GEFA and LIM. J. Climate, 25, 6817-6834, https://doi.org/10.1175/JCLI-D-11-00630.1.

Mantua, N. J., S. R. Hare, Y. Zhang, J. M. Wallace, and R. C. Francis, 1997: A Pacific interdecadal climate oscillation with impacts on salmon production. Bull. Amer. Meteor. Soc., 78 1069-1079, https://doi.org/10.1175/1520-0477(1997)078<1069: APICOW $>2.0 . \mathrm{CO} ; 2$.

Masunaga, R., H. Nakamura, T. Miyasaka, K. Nishii, and Y. Tanimoto, 2015: Separation of climatological imprints of the Kuroshio Extension and Oyashio fronts on the wintertime atmospheric boundary layer: Their sensitivity to SST resolution prescribed for atmospheric reanalysis. J. Climate, 28 1764-1787, https://doi.org/10.1175/JCLI-D-14-00314.1.

Minobe, S., A. Kuwano-Yoshida, N. Komori, S.-P. Xie, and R. J. Small, 2008: Influence of the Gulf Stream on the troposphere. Nature, 452, 206-209, https://doi.org/10.1038/nature06690.

Nakamura, H., T. Sampe, Y. Tanimoto, and A. Shimpo, 2004: Observed associations among storm tracks, jet streams and midlatitude oceanic fronts. Earth's Climate: The Ocean-Atmosphere Interaction, Geophys. Monogr., Vol. 147, Amer. Geophys. Union, 329-345.

Newman, M., and Coauthors, 2016: The Pacific decadal oscillation, revisited. J. Climate, 29, 4399-4427, https://doi.org/10.1175/ JCLI-D-15-0508.1.

O'Reilly, C. H., and A. Czaja, 2015: The response of the Pacific storm track and atmospheric circulation to Kuroshio Extension variability. Quart. J. Roy. Meteor. Soc., 141, 52-66, https:// doi.org/10.1002/qj.2334

Pak, G., Y.-H. Park, F. Vivier, Y.-O. Kwon, and K.-I. Chang, 2014: Regime-dependent nonstationary relationship between the East Asian winter monsoon and North Pacific
Oscillation. J. Climate, 27, 8185-8204, https://doi.org/ 10.1175/JCLI-D-13-00500.1.

Parfitt, R., A. Czaja, and Y.-O. Kwon, 2017: The impact of SST resolution change in the ERA-Interim reanalysis on wintertime Gulf Stream frontal air-sea interaction. Geophys. Res. Lett., 44, 3246-3254, https://doi.org/10.1002/2017GL073028.

Park, S., C. Deser, and M. A. Alexander, 2005: Estimation of the surface heat flux response to sea surface temperature anomalies over the global oceans. J. Climate, 18, 4582-4599, https:// doi.org/10.1175/JCLI3521.1.

Peng, S., and J. S. Whitaker, 1999: Mechanisms determining the atmospheric response to midlatitude SST anomalies. J. Climate, 12, 1393-1408, https://doi.org/10.1175/1520-0442 (1999)012<1393:MDTART>2.0.CO;2.

W. A. Robinson, and M. P. Hoerling, 1997: The modeled atmospheric response to midlatitude SST anomalies and its dependence on background circulation states. J. Climate, $\mathbf{1 0}$, 971-987, https://doi.org/10.1175/1520-0442(1997)010<0971: TMARTM>2.0.CO;2.

Qiu, B., S. Chen, N. Schneider, and B. Taguchi, 2014: A coupled decadal prediction of the dynamic state of the Kuroshio Extension system. J. Climate, 27, 1751-1764, https://doi.org/ 10.1175/JCLI-D-13-00318.1.

Révelard, A., C. Frankignoul, N. Sennéchael, Y.-O. Kwon, and B. Qiu, 2016: Influence of the decadal variability of the Kuroshio Extension on the atmospheric circulation in the cold season. J. Climate, 29, 2123-2144, https://doi.org/10.1175/ JCLI-D-15-0511.1.

Reynolds, R. W., T. M. Smith, C. Liu, D. B. Chelton, K. S. Casey, and M. G. Schlax, 2007: Daily high-resolution-blended analyses for sea surface temperature. J. Climate, 20, 5473-5496, https:// doi.org/10.1175/2007JCLI1824.1.

Rivière, G., 2009: Effect of latitudinal variations in low-level baroclinicity on eddy life cycles and upper-tropospheric wavebreaking processes. J. Atmos. Sci., 66, 1569-1592, https://doi.org/ 10.1175/2008JAS2919.1.

Saji, N. H., B. N. Goswami, P. N. Vinayachandran, and T. Yamagata, 1999: A dipole mode in the tropical Indian Ocean. Nature, 401, 360-363, https://doi.org/10.1038/43854.

Schneider, N., and B. D. Cornuelle, 2005: The forcing of the Pacific decadal oscillation. J. Climate, 18, 4355-4373, https://doi.org/ 10.1175/JCLI3527.1.

Schott, F. A., S.-P. Xie, and J. P. McCreary, 2009: Indian Ocean circulation and climate variability. Rev. Geophys., 47, RG1002, https://doi.org/10.1029/2007RG000245.

Seo, H., Y.-O. Kwon, and J.-J. Park, 2014: On the effect of the East/ Japan Sea SST variability on the North Pacific atmospheric circulation in a regional climate model. J. Geophys. Res. Atmos., 119, 418-444, https://doi.org/10.1002/2013JD020523.

Smirnov, D., M. Newman, and M. A. Alexander, 2014: Investigating the role of ocean-atmosphere coupling in the North Pacific Ocean. J. Climate, 27, 592-606, https://doi.org/10.1175/JCLI-D-13-00123.1.

,,-- Y.-O. Kwon, and C. Frankignoul, 2015: Investigating the local atmospheric response to a realistic shift in the Oyashio sea surface temperature front. J. Climate, 28, 1126-1147, https://doi.org/10.1175/JCLI-D-14-00285.1.

Stewart, G. W., 1987: Collinearity and least squares regression. Stat. Sci., 2, 68-84, https://doi.org/10.1214/ss/1177013439.

Straus, D. M., and J. Shukla, 2002: Does ENSO force the PNA? J. Climate, 15, 2340-2358, https://doi.org/10.1175/1520-0442 (2002)015<2340:DEFTP > 2.0.CO;2.

Taguchi, B., H. Nakamura, M. Nonaka, N. Komori, A. KuwanoYoshida, K. Takaya, and A. Goto, 2012: Seasonal evolutions 
of atmospheric response to decadal SST anomalies in the North Pacific subarctic frontal zone: Observations and a coupled model simulation. J. Climate, 25, 111-139, https://doi.org/ 10.1175/JCLI-D-11-00046.1.

Takaya, K., and H. Nakamura, 2001: A formulation of a phaseindependent wave-activity flux for stationary and migratory quasigeostrophic eddies on a zonally varying basic flow. J. Atmos. Sci., 58, 608-627, https://doi.org/10.1175/1520-0469(2001)058<0608: AFOAPI $>2.0 . \mathrm{CO} ; 2$.

Trenberth, K. E., and J. W. Hurrell, 1994: Decadal atmosphereocean variations in the Pacific. Climate Dyn., 9, 303-319, https://doi.org/10.1007/BF00204745.

, and D. P. Stepaniak, 2001: Indices of El Niño evolution. J. Climate, 14, 1697-1701, https://doi.org/10.1175/1520-0442(2001)014<1697: LIOENO $>2.0 . \mathrm{CO} ; 2$.

G. W. Branstator, D. Karoly, A. Kumar, N.-C. Lau, and C. Ropelewski, 1998: Progress during TOGA in understanding and modeling global teleconnections associated with tropical sea surface temperatures. J. Geophys. Res., 103, 14 291-14 324, https://doi.org/10.1029/97JC01444.

von Storch, H., and F. W. Zwiers, 1999: Statistical Analysis in Climate Research. Cambridge University Press, 484 pp.

Wang, C. Z., 2002: Atlantic climate variability and its associated atmospheric circulation cells. J. Climate, 15, 1516-1536, https:// doi.org/10.1175/1520-0442(2002)015<1516:ACVAIA >2.0.CO;2.

Wen, N., Z. Liu, Q. Liu, and C. Frankignoul, 2010: Observed atmospheric responses to global SST variability modes: A unified assessment using GEFA. J. Climate, 23, 1739-1759, https://doi.org/10.1175/2009JCLI3027.1.

Yu, L., and R. A. Weller, 2007: Objectively analyzed air-sea heat fluxes for the global ice-free oceans (1981-2005). Bull. Amer. Meteor. Soc., 88, 527-539, https://doi.org/10.1175/ BAMS-88-4-527.

Zebiak, S. E., 1993: Air-sea interactions in the equatorial Atlantic region. J. Climate, 6, 1567-1586, https://doi.org/10.1175/ 1520-0442(1993)006<1567:AIITEA > 2.0.CO;2. 